Tjalling C. Koopmans Research Institute Tpllizh. Aoopmen

Discussion Paper Series nr: 14-12

\title{
Efficiency and competition in the Dutch non-life insurance industry
}

Effects of the 2006 health care reform

Jacob A. Bikker

Adelina Popescu 


\title{
Tjalling C. Koopmans Research Institute Utrecht School of Economics Utrecht University
}

Kriekenpitplein 21-22

3584 EC Utrecht

The Netherlands

telephone $\quad+31302539800$

fax +31302537373

website www.koopmansinstitute.uu.nl

The Tjalling C. Koopmans Institute is the research institute and research school of Utrecht School of Economics.

It was founded in 2003, and named after Professor Tjalling C. Koopmans, Dutch-born Nobel Prize laureate in economics of 1975.

In the discussion papers series the Koopmans Institute publishes results of ongoing research for early dissemination of research results, and to enhance discussion with colleagues.

Please send any comments and suggestions on the Koopmans institute, or this series to L.M.vanDort@uu.nl

ontwerp voorblad: WR IK U trecht

\author{
How to reach the authors \\ Please direct all correspondence to the first author. \\ Jacob A. Bikker \# \\ Adelina Popescu\# \\ Utrecht University \\ Utrecht School of Economics \\ Kriekenpitplein 21-22 \\ 3584 TC Utrecht \\ The Netherlands. \\ E-mail: L.A.Bikker@DNB.NL \\ \# De Nederlandsche Bank \\ Westeinde 1 \\ 1017 ZN Amsterdam
}

This paper can be downloaded at: http: //

www.uu.nl/rebo/economie/discussionpapers 


\title{
Efficiency and competition in the Dutch non- life insurance industry: Effects of the 2006 health care reform
}

\author{
Jacob A. Bikkerab \\ Adelina Popescu ${ }^{b}$ \\ aUtrecht School of Economics \\ Utrecht University \\ ${ }^{\text {b}}$ De Nederlansche Bank \\ Amsterdam
}

September 2014

\begin{abstract}
This paper investigates the cost efficiency and competitive behaviour of the nonlife - or property and casualty - insurance market in the Netherlands over the period 1995-2012. We focus on the 2006 health care reform, where public health care insurance has been included in the non-life insurance sector. We start with estimating unused scale economies and find that after the health care reform in 2006 , unused scale economies are, at $21 \%$, much higher than before the reform $(4 \%)$, pointing to a relative increase of fixed costs. Scale inefficiencies are generally higher for smaller insurance and lower for large insurance companies. As a benchmark, we also estimate scale economies for non-health lines of business (LOB), which range from $5 \%$ to $10 \%$. To measure competition directly, we apply a novel approach that estimates the impact of marginal costs as indicator of inefficiency on either market shares or profits. Over time, competition in health insurance has increased significantly, but the inclusion of the (non-competitive) public health care funds in the health insurance sector in 2006 caused a fall in the average level of competitive pressure. After the reform, competition continued to improve. In the non-health LOB non-life insurance, we find similar significant effects of efficiency on both market shares. The non-life effects are weaker than in life insurance, banking and non-financial sectors, suggesting less heavy competition.
\end{abstract}

Keywords: competition, concentration, efficiency, non-life insurance, health care insurance, performance-conduct-structure model, scale economies, scope economies.

JEL classification: G22, H51, L11-L13.

\section{Acknowledgements}

The second author was intern at DNB during the time this paper was written. The authors are grateful to Paul Cavelaars and participants of the 18th Annual Conference of the Asia-Pacific Risk and Insurance Association (APRIA), 27-30 July 2014, Moscow, for useful comment, and Jack Bekooij for excellent research assistance. Views expressed are those of the authors and do not necessarily reflect official positions of DNB. 


\section{Introduction}

In recent years, competition in the Dutch health insurance sector has undergone a series of changes, mostly facilitated by a fundamental reform of the health care system in 2006, which aimed to increase cost efficiency and innovation (Daley and Gubb, 2011). Under the new regime, the dual system of public and private insurance was replaced with a single compulsory health insurance scheme in which insurance providers compete for customers in a free market. The new regulatory structure also meant that the position of the government changed from a direct steering role (in terms of prices and volumes) to that of a supervisor surveying product quality and a level playing field (Schäfer et al., 2010). ${ }^{1}$ The question we raise here is whether the new regime did indeed have the intended effect on the market. To answer it, this study examines efficiency and competitive behaviour in the health insurance market of the Netherlands, with a focus on the impact of the 2006 health reform on insurers' cost behaviour. In light of the 2006 reform package, measuring competition and efficiency is an important issue. Furthermore, there is a need for a balancing act between sufficient and effective competition and a situation in which insurers seek 'more subtle ways of risk selecting' in response to an excessively competitive environment (Daley and Gubb, 2011, p. 9).

As a benchmark, we compare our health results with estimate for the other non-life lines of business (LOB), such as fire, motor and transport, which insure risk in a similar way. ${ }^{2}$ Moreover, health care insurance is provided by both monolines (selling only one insurance type) and multilines. The existence of different lines of business and the availability of such information in our data set makes it interesting to study the degree of efficiency and competition in each of these submarkets. Furthermore, we have many more observations of the entire non-life sector including multiline insurers, than of monoline health insurers only, allowing much more reliable estimates. Finally, this study will also provide insight into the structure of the non-life insurance market with respect to insurers' decision on whether to specialize or, take advantage of scope economies.

The health and other non-life LOB insurance market are important actors in resolving risk and uncertainty and are significant, both in terms of volume and as a share of expenditure for the average household. The Dutch non-life insurance market is considered mature and is the tenth largest in the world in terms of gross written premiums (Capgemini, 2012), in part due to the inclusion of the basic health insurance, which is in other countries part of social security. In 2012, net premiums amounted to $€ 53$ billion and total assets equalled $€ 76$ billion. According to a report of the Dutch Insurance Association, in 2008 non-life insurance spending represented 11\% of total spending for a three-person household (of which 8 percentage points for health care insurance), compared to only $2 \%$ for life insurance (Verbond van Verzekeraars, 2011).

\footnotetext{
1 The parliament remains responsible for the composition of the basic health insurance package, while the Minister of health prescribes the 'cost' price of the basic health care package.

2 Unlike in other countries, in the Netherlands the non-life sector includes the health, disability and accident insurance. Non-life may be referred to as Property and Liability (P-L) or Property and Casualty (P-C) insurance.
} 
Measuring competition directly is difficult, particularly on a more detailed level, due to lack of data on the costs and prices of individual insurers and lines of business. Therefore, efficiency is a measure that is frequently used as an indirect substitute. The underlying assumption is that strong competition incentivizes insurers to become more efficient, for example by forcing managers to reduce marginal costs in order to remain profitable (Raith, 2003; Hay and Liu, 1997), so that a high efficiency estimate would indicate the existence of strong competition. In order to capture this effect, we will measure scale efficiency by estimating a translog cost function. In addition, we will employ a competition measure, which we refer to as the performance-conduct-structure (PCS) model, advanced by Hay and Liu (1997) and Boone (2001, 2008). Underlying this approach is the idea that in a competitive environment, insurers experience an increase in market share, if they pass on their efficiency gain (fully or partly) by lowering their output prices. Insurers enjoy also higher profits, due to a larger market share and - if they keep part of their efficiency gains - a higher profit margin. In other words, efficiency is rewarded more highly amid heavier competition. For an overview, see Bikker and Van Leuvensteijn (2014). This measure has been employed in the past for the life insurance market (Bikker and Van Leuvensteijn, 2008; Bikker, 2012) but never, to the extent of our knowledge, for non-life insurance. The PCS indicator would measure the extent to which existing efficiency differences between insurers are reflected in performance divergences. While there are alternative methods to measure competition, such as the traditional Lerner-index, the Panzar-Rosse model, concentration indices, the price-cost margin model, most of them are hampered by data insufficiencies, theoretical flaws or empirical failings (Bikker and Bos, 2008).

Although the empirical research on competition and efficiency in the insurance industry is not highly developed, Cummins and Weiss (2014) identify 74 studies spanning the period 1983-2011 and covering different aspects of both non-life and life insurance, with roughly half of them studying the US market. Previous research into non-life insurance revealed substantial scale economies averaging above 10\% for the Dutch market (Bikker and Gorter, 2011). Similar results were found in studies focusing on the US and several European countries (Cummins and Weiss, 2014; Kasman and Turgutlu, 2009; Fenn et al., 2008; Cummins and Rubio-Misas, 2006; Fecher et al., 1991). This paper contributes to the literature by applying the PCS measure of competition, which has to date been rarely used. We use a unique, not publicly available data set for the Dutch non-life industry during 19952012, which captures the effects of the 2006 health care reform package. The results are interesting for other countries too, given that elements of this reform are also found, e.g., in the Swiss and German health care systems (Greß, Manouguian, and Wasem, 2007).

The remainder of the paper is organized as follows. Section two provides background information on the organization and development of the Dutch insurance market. Section three reviews the literature on competition and efficiency in the non-life insurance industry. Section four discusses the methodology behind estimations of competition, while the next section provides an 
overview of the data. The empirical findings and a brief comparison with similar results in the life insurance studies are shown in Section six. The last section provides concluding remarks.

\section{The Dutch non-life insurance industry}

In order to gain a better understanding of the industry, this section presents an outline of the non-life insurance sector in the Netherlands and the main recent events shaping its development. Prior to January 2006, the Dutch health care system featured a complex structure of private and public insurance entities under the Compulsory Health Insurance Act ('Ziekenfondswet'), divided into three compartments. Basic health insurance was provided in the first compartment: the mandatory Health Insurance Fund (HIF: Ziekenfonds) for everyone below the so-called HIF income level. Covering 62\% of the population, the HIF was financed through income-dependent contributions paid by employees, employers and social security providers. Those not qualifying for the HIF scheme could take out voluntary private health insurance, carrying a flat-rate insurance premium. HIF insured could expand the cover of their basic health insurance on the private health insurance market. A final compartment consisted of a public insurance scheme providing long-term care for the chronically ill funded out of social security premiums.

In 2006, the most comprehensive health insurance reform in the Netherlands since the Second World War merged the first two compartments into a single private but mandatory scheme. Private insurers provide a single compulsory basic health scheme and compete for business on the price of that package. All insured pay a flat rate for the basic package, while all employers pay an incomedependent premium. The benefits are fully standardized and insurers are obliged to accept all applicants regardless of their health profile (i.e. no 'cherry picking'). Due to this requirement, the system is one of managed competition, supervised by independent bodies, with insurers negotiating prices with health care providers and policyholders being free to change insurers every year (Schäfer et al., 2010). Insurers with a proportionally older clientele are compensated by insurers with relatively green clients. The insured may supplement their basic package with extensions supplied by the market. The ultimate goal of the reform was 'to encourage health insurers to increase the efficiency of the health-care provision by becoming prudent buyers of health services on behalf of their customers' (Van den Ven and Schut, 2009, p. 253).

The Dutch non-life insurance industry consists of five lines of business: (i) health which also includes disability and accident insurance, (ii) motor vehicle, (iii) marine, transport and aviation, (iv) fire and other property risk, and (v) other (or miscellaneous) non-life insurance, including, among others, credit, legal expenses and travel insurance. Since 2006, health insurance has replaced both the former public-sector Health Insurance Funds and the voluntary private insurance schemes for higher income beneficiaries. The statistical break of 2006 is evident from Fig. 1: the share of health and accident premiums has increased dramatically in that year due to the inclusion of the HIFs, which 
almost doubled the premiums written in the non-life sector; by the way, health was already the major component of the non-life sector before 2006. The transport insurance has shrunk, even though the Netherlands has large and important ports. One explanation for this may be strong competition, especially from the London market (Oosenbrug, 2007).

Fig. 1: Composition of gross non-life premiums by line of business over time

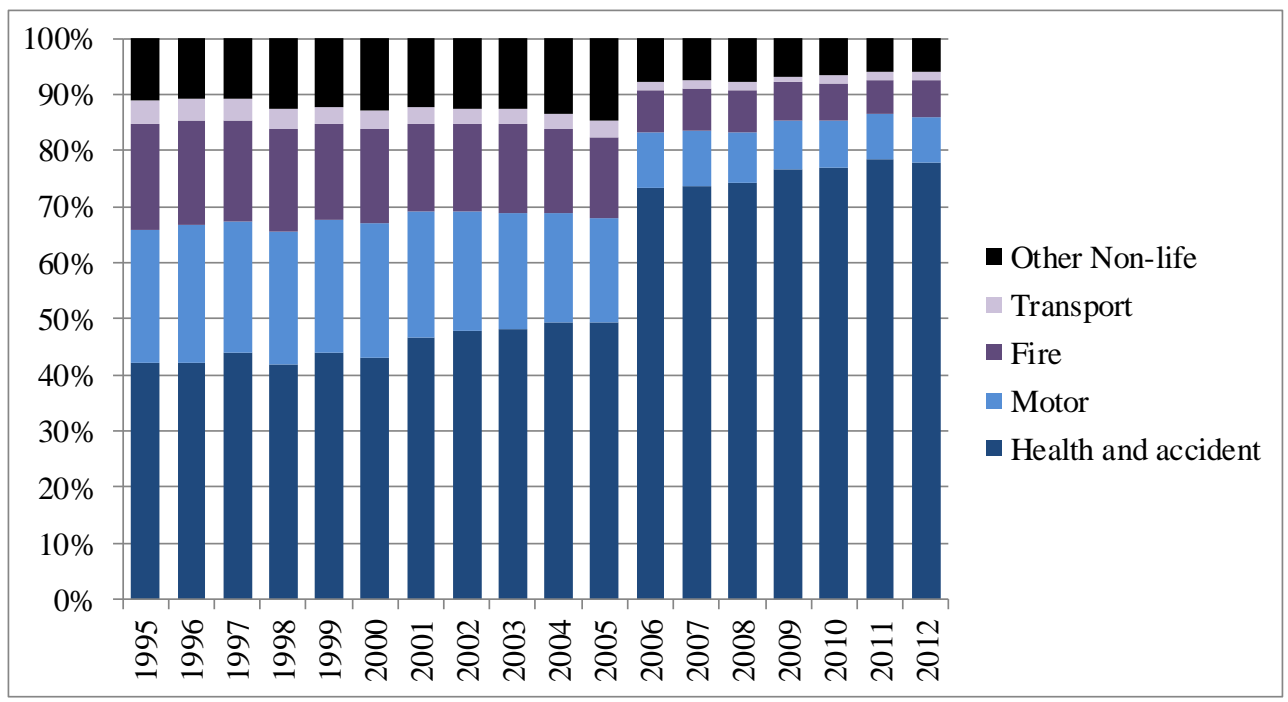

The 2012 numbers point to a significant Dutch non-life industry in terms of per capita premiums (€ 3,295), market share (10.8\% of total European premiums; Swiss Re, 2013) and share of GDP (9.4\% in 2012 compared to only $4.6 \%$ in 2005 and $9.5 \%$ in 2006, where the latter jump shows the effect of the structural break). Although in the years 2006 and 2007 health carriers were accepting losses in order to build market share, more recently we have seen a steady increase in health insurance premiums (Swiss Re, 2011; Leu et al., 2009). The reform year also marked a one-time peak in customer mobility for health insurance, when in the first months of 2006 the market registered $21 \%$ of consumers changing health insurers, only to return to a low 4.4\% in 2007 and 3.6\% in 2008 (Leu et al., 2009). In recent years this percentage recovered to $6.5 \%$.

Of the 168 licensed non-life insurance firms that operated in 2010, 3 an estimated half are affiliated to one of the nine largest insurance groups, which control $70 \%$ of the market. Even though consolidation had been ongoing in the Dutch non-life insurance market, the flaring of reform proposals in the public debate triggered a fresh wave of mergers and acquisitions in anticipation of

\footnotetext{
3 Prior to 2004, licenses were granted by the Pensions and Insurance Supervisory Authority (In Dutch: 'Pensioen- \& Verzekeringskamer'). Since 2004, this institution has been integrated with the Dutch Central bank, which is now the sole issuer of insurer licenses for the Netherlands. We also count as operating firms that have stopped receiving premiums but are still paying out claims.
} 
new laws. This is evident from Fig. 2, as the Herfindahl-Hirschman concentration index (HHI) ${ }^{4}$ increases from 2004 onwards, peaking just before the reform. According to Van der Lee (2010) 'private insurers and HIFs merged into large companies in order to strengthen their competitive position and to obtain sufficient countervailing power especially in relation to health care providers' (as cited in Schäfer et al., 2010, p. 34). After the reform we see a steady development, even a slight decrease in concentration signaling new entrances (viz. the former Ziekenfondsen), before consolidation resumed in 2010 and 2011.

Fig. 2: HHIs for the Dutch non-life insurance industry: health and aggregate

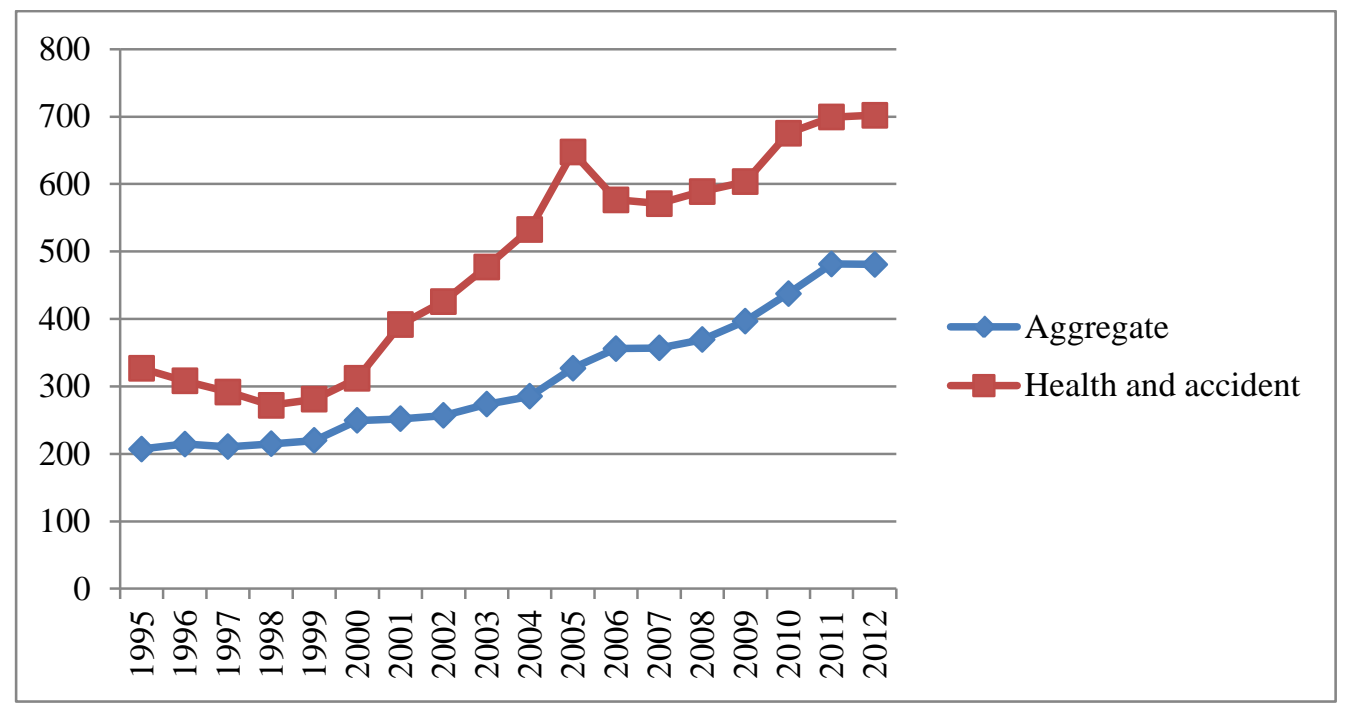

Although there is a wide variety of distribution channels - such as independent and tied agents, bank offices, direct writers, underwriting agents, brokers, car dealers, supermarkets - according to Bikker and Gorter (2011), agents are the most important distribution channel for non-life insurance policies, capturing over $50 \%$ of premiums (compared to only $20 \%$ in Germany and the UK). Another $10 \%$ is sold through affiliated banks and roughly $20 \%$ is sold by direct writers (Oosenbrug, 2007).

\section{Literature review}

Although not vast, the literature on non-life insurance touches upon a variety of topics and employs a plethora of methodologies to assess competition and efficiency. Articles on competition and efficiency all share the assumption that stronger competition forces insurers to operate more efficiently. Increased observed efficiency could be indicative of increased competition. The most frequently

\footnotetext{
${ }^{4} \mathrm{HHI}$ is defined as the sum of the squared market share, expressed in percentages, so that theoretically, the $\mathrm{HHI}$ ranges between 0 and 10,000. Numbers are based on health insurance premium income and measured at aggregate level during 1995-2012.
} 
employed way of measuring efficiency is by calculating scale economies. In insurance as elsewhere, the larger the company is, the better able it is to spread its fixed costs over its many clients .

When studying the US Property-Liability (P-L) industry across the sample period 1993-2009, Cummins and Xie (2013) using data envelopment analysis (DEA), find that P-L insurers realize increasing returns to scale in the smallest six size deciles and decreasing returns to scale in the largest four. They also find that when an insurer is more diversified in different LOBs and/or geographically, improvements in scale efficiency are more likely. Finally, they determine that cost inefficiency averages not less than $49 \%$, and over the period studied there was an increase in both scale and allocative efficiency. Using a translog cost function, Bikker and Gorter (2011) find that for the Dutch market substantial scale economies exist, averaging above 10\% appearing larger for smaller insurers and vice versa. They also employ a thick frontier analysis to determine that the majority of firms operate with increasing returns to scale, while the largest insurers have decreasing returns to scale and scale efficiency did not improve over the sample period 1995-2005. Similarly, Fecher et al. (1991) identify economies of scale in the French non-life insurance industry. Cummins and Rubio-Misas (2006) also apply DEA to find that for Spanish insurers average scale economies of $10 \%$ exist, which are larger for smaller firms. Kasman and Turgutlu (2009) make a similar analysis for Turkey and observe significant scale economies for all size classes, while small insurers are more efficient than their larger counterparts. Fenn et al. (2008) estimate efficiency at the European level in fourteen countries and reveal that, on average, insurers operate with increasing returns to scale. Hirao and Inoue (2004) also use a translog cost function and find significant scale economies for Japanese non-life insurers, a result that contrasts with Toivanen (1997), who measures diseconomies of scale for the Finnish non-life industry at firm level. By analyzing branches separately, Toivanen finds, remarkably enough, economies of scale at branch level.

Using Stochastic Frontier Analysis (SFA), Fenn et al. (2008) estimate cost efficiency scores for the non-life insurance industry in several European countries. For the Netherlands, a small but steady decline has been observed from a score of 0.946 in 1995 to 0.936 in 2001, where insurers that operate at the technical possibility frontier have a score of 1. Using the same methodology, Rai (1996) finds that, for the overall Dutch insurance industry in the period 1988-1992, the inefficiency estimate is 37\% for large insurers and 28\% for small firms. Eling and Luhnen (2010) use both SFA and DEA and study cost efficiencies in a 36 country sample over 2002-2006. Their results show that cost efficiency is 39\% for non-life insurance when using the DEA methodology and no less than $74 \%$ when using SFA. According to Cummins and Rubio-Misas (2006), cost efficiency for Spanish insurers is relatively low, with estimates from 1998 averaging 30\%, obtained using the DEA methodology. As the methodologies and approaches differ, efficiency levels cannot always be compared.

One of the trends observed for the Dutch non-life insurance market is consolidation, a reduction in both the number of insurers and in lines of business (LOB) per insurer (Bikker and Gorter, 2011). The 'strategic focus' hypothesis states that through dedicating resources only to the 
core business and core competencies of a firm, added value is created by reducing the principal-agent incentives problem. Under such a focused strategy, managers are assumed to be less prone to adding unproductive business to serve their own interests and less able to invest in projects with negative net present value (Jensen, 1986; Berger et al., 2000). Opposed to this view is the conglomeration hypothesis, in which diversification creates firm value through economies of scope. These arise from jointly producing a number of services, a situation where costs are lower than the aggregate costs of producing them separately (Teece, 1980). For the insurance companies, we can think of synergy due to overlapping marketing channels, investment costs and sales costs, although not all business line combinations may have the same level of cost complementarity. In addition to cost scope economies, revenue scope economies occur where consumers are offered a 'one-stop shopping' alternative for all their insurance needs (Berger et al., 2000; Bikker and Gorter, 2011).

There is evidence supporting each side of the debate on which of these policies would increase efficiency. Past research shows that for a non-financial firm the strategic focus hypothesis is supported over the conglomeration one. However for the financial industry the results are less straightforward and appear to be under-researched (Berger et al., 2000). Within life insurance, some authors find significant cost scope economies in Canada (Kellner and Mathewson, 1983), while for the US neither Yuengert (1993) nor Grace and Timme (1992) find evidence of economies of scope. Meador, Harley and Schellhorn (1998) and Berger et al. (2000), by contrast, conclude to efficiency benefits from diversification, in support of the conglomeration hypothesis for the US market. Turning to non-life insurance, one of the few studies focusing on this sector is Toivanen (1997), revealing modest cost economies of scope in the Finnish industry. Hirao and Inoue (2004) also find significant economies of scope for the Japanese non-life insurance market. By analyzing both life and non-life industries using a DEA methodology, Cummins et al. (2010) conclude that strategic focus is superior to conglomeration in the insurance industry and particularly that cost scope economies realized by nonlife insurers are offset by revenue scope diseconomies.

More recent hypotheses about conglomeration and strategic focus include the role of uncertainty in driving the results of such a study. More specifically, expanding the scope may be more beneficial 'when there is a high degree of uncertainty about the type of skills needed to successfully undertake a new activity, when unexpected profitability is relatively high, and when competition in the firm's existing business is sufficiently low to generate the profits needed to undertake the new activity’ (Berger et al., 2000). The remaining body of literature focuses on the impact of organisational form on efficiency (mutual versus stock insurers), effects coming from different aspects of market structure (regulatory environment, foreign ownership, public listing), the effect of mergers and acquisitions as well as cross-country comparisons. ${ }^{5}$

\footnotetext{
5 Cummins and Weiss $(2000,2014)$ provide a comprehensive review of the insurance literature.
} 


\section{Measuring competition and efficiency}

In order to measure competition, we first estimate efficiency through scale economies, as an indirect measure of competition, and then proceed to compute a performance-conduct-structure (PCS) indicator as a direct measure of competition.

\subsection{Economies of scale}

Economies of scale exist when the average cost of production is negatively related to a firm's output. While in some industries output is easily measured in terms of physical quantity, for a service based industry, such as insurance, one has to rely on value measures. Cummins and Weiss (2014, pp. 26-33) report an extensive debate in the literature about the most appropriate measure of output. Keeping this discussion in mind, we follow Bikker and Gorter (2011) and explore two models, one with gross premiums and one with claims paid as the first output measure (both in euro amounts), reflecting the service of covering normal risks or expected losses. Additionally, we include total assets in each model as second output measure, representing on the one hand financial services and, on the other, the coverage of extreme risks or unexpected loss. Total assets generate investment income which, under heavy competition, may allow the premium level to fall below the claim level, and hence benefit insurance clients. Total assets also act as a buffer for lagged claims, extreme losses and, in the health insurance LOB, to cover future spending due to aging of their insured client populations.

We estimate scale economies using a translog cost function (TCF) as a second-order Taylor expansion around the mean, in natural logarithms. The main advantage of this functional form, which led to its extensive use in the related literature, is its ability to take on a U-shape, so that the costs of production are high for low levels of output and then drop to a minimum point only to rise again with higher output. The TCF and alternative functional forms are investigated in Bikker (2013). The general cost function is expressed as $O C=\mathrm{f}(Y, P, T)$, with $O C$ as operational cost, $Y$ and $P$ as output volume and input prices, respectively, and $T$ as time. The related cost function for the present study is the following:

$\ln O C_{j t}=\alpha+\sum_{i} \beta_{Y i} \ln Y_{i j t}+\frac{1}{2} \sum_{i} \sum_{k} \gamma_{Y i k}\left(\ln Y_{i j t}-\ln Y_{i \bullet .}\right)\left(\ln Y_{k j t}-\ln Y_{k} ..\right)+\sum_{k} \delta_{k} X_{k j t}+u_{j t}$

$O C_{j t}$ is the total operational cost of insurer $j$ in year $t(t=1,2, \ldots, T)$, defined as the sum of management cost (or administrative cost) and acquisition cost (that is, marketing and sales cost), and $Y_{i j t}$ is output volume of type $i(i=1,2, \ldots, N)$. Operational costs and output terms are expressed in logarithms, which reduces heteroskedasticity and generates elasticities as coefficients. The model contains squares and cross-terms of output components in order to pick up any non-linearity in the cost elasticities - and hence economies of scale - across different size categories. All output types in the non-linear terms are expressed in deviation of their averages (in logarithms), calculated over all 
insurer-year combinations, $c f$. the Taylor series expansion. The average for output type $i$ is denoted as $\ln Y_{i \bullet .}$, with dots for the sub-indices over time and across insurance firms. The variables expressed as deviations from their averages help to split linear and quadratic effects of output on costs and simplify the interpretation of the coefficients, as explained below. $X_{k j t}$ is control variable $k(k=1,2, \ldots, L)$ and $u_{j t}$ represents the random error component. These control variables include the available input prices and a time trend. All value variables are deflated to 1995 price levels using the Consumer Price Index, in order to avoid spurious correlations.

Following the above definition of economies of scale, we express overall ray scale economies (SE) for insurer $j$ in year $t$ as:

$S E_{j t}=1-\sum_{i=1}^{N}\left(\partial \ln O C_{j t} / \partial \ln Y_{i j t}\right)=1-\sum_{i=1}^{N}\left(\beta_{Y i}+\gamma_{Y i i}\left(\ln Y_{i j t}-\ln Y_{i \bullet .}\right)\right)$

The SE for the average insurer is equal to $\left(1-\sum_{i} \beta_{Y i}\right)$, the sum of linear output elasticities. In that case, the squared terms disappear due to the fact that the log outputs are presented in deviation from their geometric averages. ${ }^{6}$ If the value of SE is positive, costs increase at a slower rate than output giving evidence of economies of scale (i.e. increasing returns to scale). In this case, consolidation at firm level is more likely, as there is an incentive to capitalize on unused economies of scale. If the value of SE is negative, there is evidence of diseconomies of scale and an incentive to become more efficient by reducing scale. A SE equal to zero would indicate constant returns to scale (CRS) and point to insurers operating at minimum cost.

The final estimated translog cost model of Equation (1) reads as:

$\ln O C_{j t}=\alpha+\sum_{i} \beta_{Y i} \ln Y_{i j t}+\sum_{i} \sum_{k} \gamma_{Y i k}\left(\ln Y_{i j t}-\ln Y_{i . .}\right)\left(\ln Y_{k j t}-\ln Y_{k} ..\right)+\delta_{1} \ln$ Wage $_{t}+$ $\delta_{2}$ Stock $_{j t}+\sum_{r} \varepsilon_{r} L O B_{j r t}+\delta_{3}$ Acq $_{j t} / O C_{j t}+\delta_{4} H_{H I}+\delta_{5}$ Time $_{t}+u_{j t}$

We include an input price, viz. the wage rate, represented by the logarithm of the hourly cost of labor. In the absence of insurer-specific prices, we use the wage index for the financial sector, to take development over time into account. A dummy for stock companies (Stock, 1 for stock insurers and 0 for mutual firms) tests the effect of organizational form on cost performance. Agency theory hypothesizes that stock ownership can prove more effective due to its ability to reduce the agency costs (such as negotiation, information, litigation but also opportunity costs) associated with conflicts between owners, managers and policyholders (Mayers and Smith, 1988). In this situation, mutuals will exhibit higher costs than stock companies, all else held constant: the expense preference hypothesis. The recent credit crisis has shown that the agency theory hypothesis 'that stock ownership can prove to be more effective' may be too optimistic. The LOB variable is a set of dummies which are equal to

\footnotetext{
6 This is the first simplification which is due to the functional form in Equation (1) of the non-linear output terms, that is, in deviation from the respective (geometric) mean. The second is that the cross-output terms in Equations (1) disappear entirely in Equation (2), after taking first derivatives.
} 
one if the insurer is active in the respective line of business and is expected to capture any remaining heterogeneity related to each line of business; Miscellanous acts as reference category. The choice of distribution strategy, represented by the ratio of acquisition costs to total costs, $A c q_{j t} / O C_{j t}$, may impact highly on costs, so that a positive coefficient is expected. While the above controls (except Wages) vary at firm-level, the premium based Herfindahl-Hirschman Index (HHI) is calculated at industry level with variations limited to time. We expect a positive coefficient for this variable, as higher concentration may indicate less competition and lower pressure on companies to economize on cost. Lastly, a time variable is included to reflect technical progress, so that its coefficient is expected to be negative.

\subsection{The PCS competition model}

The well-known and often criticised structure-conduct-performance (SCP) paradigm explains performance from structure, drawing at the same time a conclusion about competition, see Bos (2004) for an overview and a critical analysis. The opposite theory, the efficiency hypothesis, follows the reversed route and explains structure from performance. In line with the latter hypothesis, Hay and Liu (1997) and Boone $(2001,2008)$ introduce a measure of competition from a model explaining structure from performance. Following Bikker (2012), we call this measure the performance-conduct-structure (PCS) indicator. This direct competition measure was applied earlier to the life insurance industry by Bikker and Van Leuvensteijn (2008) and Bikker (2012). We use Hay and Liu's (1997) theoretical model to explain the PCS indicator.

The inverse demand curve of the insurance industry is given by $p=f(Q)$, were $Q$ is the market output defined as the sum of the outputs of each insurance firm $j, Q=\sum_{j} q_{j}$. Each insurer maximizes profits by choosing $q_{j}$ in the profit function below:

$\pi_{j}=\left[f(Q)-c_{j}\right] q_{j}-F_{j}$

Where $c_{j}$ is the variable cost and $F_{j}$ is the fixed cost. The first-order condition is:

$\frac{\partial \pi_{j}}{\partial q_{j}}=p-c_{j}+q_{j} \frac{d p}{d Q} \frac{\partial Q}{\partial q_{j}}=0$

$\partial Q / \partial q_{j}$ is defined as equal to $1+\lambda_{j}$, where $\lambda_{j}=\left(1-m s_{j}\right) / m s_{j}$ reflects the conjectural variation, i.e. the expectation of firm $j$ of the extent to which changes in its own decisions will affect the output of its rival firms; $m s_{j}$ is the market share of firm $j$. If we rearrange Equation (5), divide both sides by $p$ and define $\frac{q_{j}}{p} \frac{d p}{d Q}$ as $\frac{1}{E}$, the inverse of the demand elasticity, the following equation results:

$$
\begin{aligned}
& \frac{p-c_{j}}{p}=\frac{m s_{j}}{E}\left(1+\lambda_{j}\right), \text { or } \\
& m s_{j}=\left(1-\frac{c_{j}}{p}\right) \frac{E}{1+\lambda_{j}}
\end{aligned}
$$


Equation (7) shows that a lower cost level for firm $i$ is associated with a higher market share. When $n$ insurers are considered to generate positive output levels on the market, we can sum Equation (6) across all firms $k=1, \ldots, n$ (including firm $j$ ):

$\frac{n p}{p}-\frac{\sum c_{k}}{p}=\frac{1+\sum m s_{k} \lambda_{k}}{E}$ or $p=\frac{\sum c_{k} E}{E n-1+\sum m s_{k} \lambda_{k}}$

Dividing both fraction terms on the right hand side by $E n$ yields:

$p=\left(\sum c_{k} / n\right) /\left[1-\left(1+\sum m s_{k} \lambda_{k}\right) / E n\right]$

Substituting Equation (9) in (7) yields the following:

$m s_{j}=\frac{E}{1+\lambda_{j}}\left(1-\frac{c_{j}}{p}\right)=\frac{E}{1+\lambda_{j}}\left(1-c_{j} \frac{1-\left(1+\sum m s_{k} \lambda_{k}\right) /(n E)}{\sum c_{k} / n}\right)=\frac{E}{1+\lambda_{j}}\left(1-\left(1-\frac{1+\sum m s_{k} \lambda_{k}}{n E}\right) \frac{c_{j}}{\sum c_{k} / n}\right)$

Given that in a Nash-Cournot equilibrium $\lambda_{k}=0$, the final model becomes:

$m s_{j}=E-\left(E-\frac{1}{n}\right) \frac{c_{j}}{\sum c_{k} / n}$

The coefficient of $c_{j} /\left(\sum c_{k} / n\right)$ is consistent with the hypothesis that firms with lower (relative) costs achieve higher market shares. Based on the above theoretical model, Hay and Liu (1997) develop an empirical model relating marginal costs to market shares (and profits). We adapt this model for this paper as:

$\ln M S_{j t}=\alpha+\beta_{t} \ln M C_{j t}+\gamma \ln M S_{j t-1}+\delta L O B_{j t}+\theta T_{i m e}+\varepsilon_{j t}$

The dependent variable $\ln M S_{j t}$ represents the market share of insurer $j$ in year $t$, in logarithm form to correct for heteroskedasticity. As the market shares add to one each year, we substitute the restriction $M S_{p t}=1-\sum M S_{j t}$ for each year (summing over $1,2, \ldots, p-1$ ) into the model equation by dividing each observation by that of the $p^{\text {th }}$ insurer.

$\ln \left(M S_{j t} / M S_{p t}\right)=\alpha+\beta_{t}\left(\ln M C_{j t} / M C_{p t}\right)+\gamma\left(\ln M S_{j, t-1} / M S_{p, t-1}\right)+\delta\left(L O B_{j t}-L O B_{p t}\right)+$ $\theta$ Time $_{t}+\varepsilon_{j t}$

Hereby, we apply an extension of the linear logit model, inspired by Theil (1969). Following Hay and Liu (1997), we introduce a one-year lag of the market share variable to capture lagged adaptation: a permanent change in marginal costs may have a gradual upward effect on market shares. Therefore, a positive coefficient is expected on the lagged term. The marginal cost of insurer $j$ at time $t$ is represented by the term $M C_{j t}$. Since it cannot be observed, it is estimated from the translog model in Equation (1) using the following formula: 
$M C_{j t}=\sum_{i} M C_{i j t}=\sum_{i}\left(\frac{\partial \ln O C_{j t}}{\partial \ln Y_{i j t}}\right)\left(\frac{O C_{j t}}{Y_{i j t}}\right)$

The coefficient of $\ln M C_{j t}, \beta_{t}$, an elasticity, is the PCS indicator of year $t$. This indicator is expected to have a negative sign, as more efficient firms will obtain higher market shares. In absolute terms, low negative values are interpreted as weak competition, and vice versa, while 0 would mean: no competition at all. Further, we add LOB dummies to Equations (11) and (12) in order to account for part of the possible heterogeneity, and Time to absorb developments over time. These equations start with assuming that the process of insuring non-life products is rather homogeneous, but subsequently we will test this assumption by applying our model to single LOBs. Note that marginal costs do not included unused scale (in)economies, as the constant costs are ignored. To confirm that, we have reestimated Equation (3) with MC instead of total costs, and indeed do not observe any relationship with output. Hence, reversed causality, that is potential impact of market share (size) on efficiency, is not a problem in our analyses.

Following Hay and Liu (1997) and Bikker and Van Leuvensteijn (2008), we estimate additional models with profit as an alternative performance indicator and average costs instead of marginal costs as the main independent variable. Note that profit can be seen as market share times profit margin. The profit measure captures the idea that the industry rents are an inverse function of competition, reallocating profits to the most efficient firms and proving the selection effect of competition. Although it is acknowledged that other unobserved sector-specific factors may affect the PCS indicator, we can, within bounds, compare PCS indicators across industries, and sectors, and over time.

\section{Data on non-life insurance}

We use regulatory data of the Nederlandsche Bank from the period 1995-2012. The raw data set consists of 4,113 observations, but we exclude 364 observations due to either missing data or negative values for output, cost or net premiums, as is possible for run-off firms. In terms of value losses due to exclusion, the discarded observations concern only $1.6 \%$ of total premiums. The resulting data set comprises 3,969 observations and is an unbalanced panel due to firm exits and entrances, mergers and acquisitions, and data selection. Table 1 provides an overview of the developments in the key non-life model variables over time.

Gross premiums, in prices of 2010, show a steady growth, except that in 2006 the premiums doubled due to the health care reform and the inclusion of HIFs in the non-life insurance sector. Total assets, as reserve for e.g. pending and future claims, grew even faster in the earlier years, but the HIFs typically had low capitalization. Most ratios are quite stable over time, except the more volatile 'profit margin' and 'net investment income', but they differ across health and non-health LOBs and, hence, 
Table 1. Developments in key non-life model variables over time

\begin{tabular}{lcccccc}
\hline & $\mathbf{1 9 9 5}$ & $\mathbf{2 0 0 0}$ & $\mathbf{2 0 0 5}$ & $\mathbf{2 0 0 6}$ & $\mathbf{2 0 1 0}$ & $\mathbf{2 0 1 2}$ \\
\hline Gross premiums (GP) $^{\mathrm{a}}$ & 47,993 & 65,158 & 112,213 & 218,336 & 311,649 & 374,377 \\
Total assets (TA) $^{\mathrm{a}}$ & 89,509 & 150,792 & 235,337 & 292,378 & 377,432 & 501,901 \\
Claims/GP $^{\text {Operational costs/GP }}{ }^{\mathrm{b}}$ & 0.66 & 0.69 & 0.60 & 0.77 & 0.80 & 0.82 \\
Profits/GP $_{\text {Net investment income/GP }}$ & 0.24 & 0.26 & 0.24 & 0.14 & 0.12 & 0.12 \\
GP stock insurers/GP & 0.05 & 0.04 & 0.10 & 0.04 & 0.03 & 0.04 \\
Share of stock insurers & 0.09 & 0.10 & 0.08 & 0.04 & 0.03 & 0.04 \\
Distribution ratio (Acq,) \% & 51.7 & 86.2 & 88.7 & 70.0 & 84.8 & 84.6 \\
Reinsurance/GP & 0.14 & 0.14 & 0.13 & 0.07 & 0.07 & 0.06 \\
HHI c & 0.12 & 0.13 & 0.12 & 0.10 & 0.08 & 0.07 \\
Equity/TA & 207 & 249 & 327 & 356 & 437 & 481 \\
Number of non-life insurers & 0.26 & 0.26 & 0.27 & 0.26 & 0.26 & 0.27 \\
\hline
\end{tabular}

${ }^{a}$ In thousands of euro, 2010 prices; ${ }^{b}$ Operational costs are defined as management and acquisition costs; ${ }^{\mathrm{c}} \mathrm{HHI}$ is defined as the squared percentage market shares of non-life insurance firms by year based on gross premiums.

jump in 2006 (see also the next tables). The share of stock-based insurers in numbers is quite stable, exept for the jump in 2010 but expressed in gross premiums, the share increases gradually at the cost of mutual firms, apart from a dip in 2006. Continuously, equity is slightly over a quarter of total assets. The number of non-life insurers fell particularly rapidly in the final years, pushing up the HHI concentration index .

Disaggregation of the key variables to LOBs is needed if one is to focus on health care insurance. However, our data set regards non-life insurers in their entirety. Nevertheless Tables 2 and 3 provide useful information on the key indicators and model variables for the various non-life LOBs for 2012. Table 2 provides pure LOB data, but only on monoline insurers, ignoring part of the LOBspecific markets. Further, the last column in this table shows data on all multiline insurers. Table A.1 in the appendix approximates the LOB data 'from above' by including all non-life insurers, active in the respective LOB. This table guarantees that all LOB activities are included, but the key characteristics are less LOB-specific. For single LOB model estimations we will use the pure LOB data of Table 2. We see that monoline health insurers take two-thirds of the non-life market, while health care insurance is also offered by multiline firms. Health monolines have the largest claim ratio at $89 \%$, and lowest profits (5\%, among the monolines), costs (5\%), distribution cost (1\%) and reinsurance (4\%), all as share of gross premiums In addition, among the monolines, health has the lowest Net investment income (3\%). Market concentration is above average at an HHI of 799 on a scale of 10,000 , while the percentage of stock insurers in numbers at $80.4 \%$ is the highest among the monolines.

'Fire' and 'other' monolines have only small shares of their markets, but their activities are also carried by multiline insurers. These two monoline categories differ strongly with claim ratios ranging from only 0.31 to 0.33 , and higher - but varying - costs, distribution and reinsurance ratios. In 
regards to the equity to total assets ratio, Fire has the largest buffers at $62 \%$. The number of Transport (5) and Motor (1) monolines is very limited.

Table 2. Sample averages of single non-life insurance lines of business (2012)

\begin{tabular}{|c|c|c|c|c|c|c|}
\hline & \multirow[t]{2}{*}{ Total } & \multicolumn{4}{|c|}{ Single lines of business $^{\mathrm{a}}$} & \multirow{2}{*}{$\begin{array}{c}\text { Multi- } \\
\text { lines }\end{array}$} \\
\hline & & Health & Fire & Transport & Other & \\
\hline Gross premiums $(\mathrm{GP})^{\mathrm{C}}$ & 374,377 & 881,116 & 5,708 & 9,182 & 126,503 & 274,460 \\
\hline Total assets (TA) ${ }^{\mathrm{c}}$ & 501,901 & 835,674 & 12,158 & 18,471 & 305,478 & 654,663 \\
\hline Claims/GP & 0.82 & 0.89 & 0.38 & 0.44 & 0.25 & 0.66 \\
\hline Operational costs ${ }^{\mathrm{b}} / \mathrm{GP}$ & 0.12 & 0.05 & 0.34 & 0.24 & 0.35 & 0.31 \\
\hline Profits/GP & 0.04 & 0.05 & 0.10 & 0.09 & 0.08 & 0.02 \\
\hline Net investment income/GP & 0.04 & 0.03 & 0.05 & 0.06 & 0.04 & 0.01 \\
\hline GP stock insurers/GP & 84.6 & 79.9 & 52.8 & 4.1 & 97.6 & 98.3 \\
\hline$\%$ of stock insurers & 65.1 & 80.4 & 26.3 & 20.0 & 70.0 & 84.0 \\
\hline Distribution ratio (Acq.) & 0.06 & 0.01 & 0.15 & 0.03 & 0.13 & 0.21 \\
\hline Reinsurance/GP & 0.07 & 0.04 & 0.20 & 0.28 & 0.54 & 0.10 \\
\hline $\mathrm{HHI}^{\mathrm{d}}$ & 481 & 799 & 507 & 2,847 & 5,087 & 930 \\
\hline Share of total non-life market ${ }^{\mathrm{e}}$ & 100.0 & 72.7 & 0.4 & 0.1 & 2.3 & 24.6 \\
\hline Equity/TA & 0.27 & 0.30 & 0.62 & 0.41 & 0.32 & 0.22 \\
\hline Number of insurers & 149 & 46 & 38 & 5 & 10 & 50 \\
\hline
\end{tabular}

Notes: ${ }^{\text {a }}$ The LOB numbers refer strictly to monoline companies offering only the respective LOB insurance. 'Mixed' contains all insurers with more than one LOB. We do not show the LOB 'Motor', which in 2012 only contains one monoline; ${ }^{\mathrm{b}}$ In thousands of euro, 2010 prices; ${ }^{\mathrm{c}}$ Operational costs are defined as management and acquisition costs; ${ }^{\mathrm{d}} \mathrm{HHI}$ is defined as squares of the 2012 market shares, based on gross premiums of, respectively, (i) all firms in the total market (Column 1), (ii) the respective LOB-specific insurers in the respective LOB submarkets (Columns 2-5), and (iii) the multilines in the multiline markets (Column 6); in percentages; ${ }^{\mathrm{e}}$ Based on gross premiums.

The straight line in Fig. 3 presents the per unit cost figures for insurers of different sizes, based on gross premiums, while the striped lines indicate the averages of the highest and lowest cost quartile. The unit costs fall sharply with size, indicating scale economies. Of course, we need regression model (11) to take all relevant explanatory variables into account and to measure unit cost more precisely. The spread of unit costs within each size class is huge for small firms, indicating heterogeneity,

Fig. 3. Average cost by quartile and by insurer size (1995-2012)

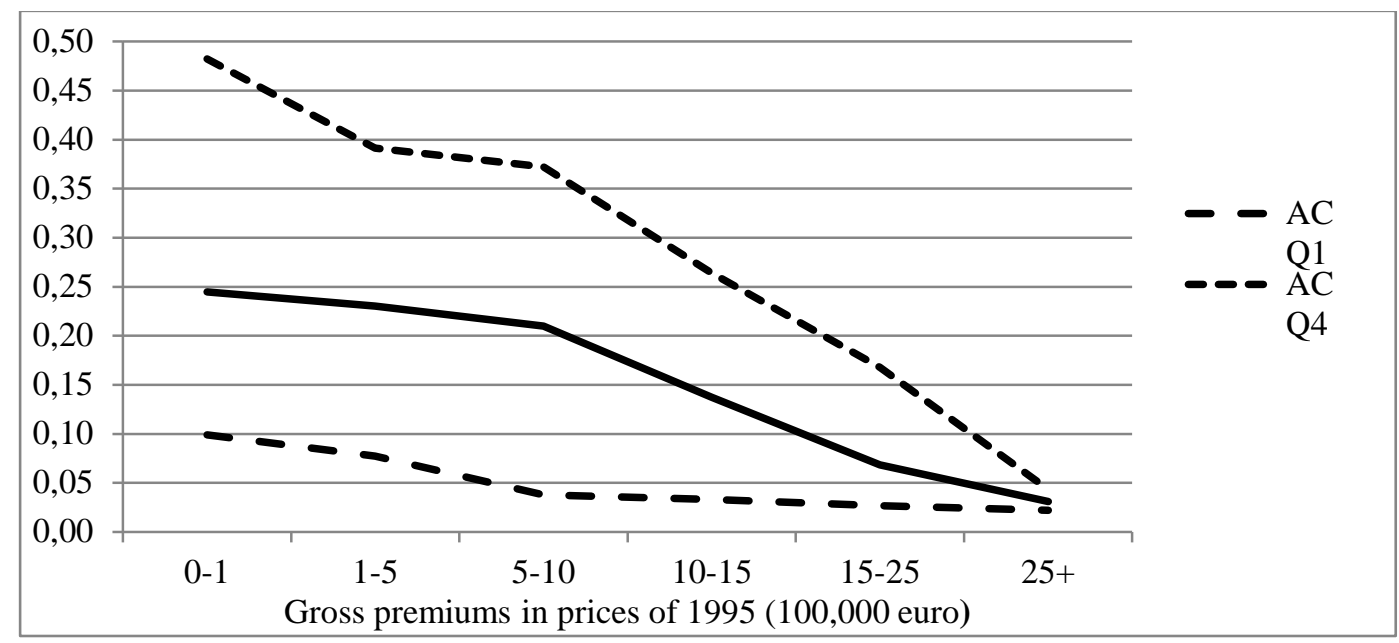

Notes: Average costs are total operational costs over gross premiums. AC Q4 and AC Q1 represent the mean average cost for the highest and lowest cost quartiles, respectively. 
inefficiency or a combination of the two. This spread falls gradually for larger insurers, and almost disappears in the largest size class.

The top panel of Table 3 shows the market shares of different insurer classes as well as the percentage of assets held, while the lower part presents the evolution in the number of insurance companies over time and by specialization. Over the sample period, the number of non-life firms decreased from 258 to 149, while the market shares all went up over time, except for the structural break in 2006. Insurer sizes increased substantially and there is clear evidence of consolidation. The lower panel of Table 3 shows also that the monoline business model is by far the preferred one, mostly due to ease of establishment and ease of management (Bikker and Gorter, 2011). The decline in 5lines is largest at -25 , in absolute terms, while that in 4-lines is largest in relative terms, with the number of firms dropping by $74 \%$. Monolines gained ground in terms of market share as well, helped by the 2006 reform. Consolidation is, therefore, more evident among multiline firms. Apparently, the benefits of specialization have outweighted that of scope economies.

Table 3. Concentration and number of insurers, by specialization and over time

\begin{tabular}{|c|c|c|c|c|c|c|c|c|c|}
\hline \multirow{3}{*}{ Year } & \multicolumn{9}{|c|}{ I. Market share of the largest insures, based on total assets or gross premiums (\%) } \\
\hline & \multicolumn{3}{|c|}{ Total assets } & \multicolumn{6}{|c|}{ Gross premiums } \\
\hline & Top 5 & Top 10 & Top 20 & & & Top 10 & Top 20 & Monoline & Multiline \\
\hline 1995 & 29 & 41 & 57 & & & 37 & 54 & 34 & 66 \\
\hline 2000 & 30 & 44 & 62 & & & 39 & 58 & 30 & 70 \\
\hline 2005 & 35 & 51 & 69 & & & 48 & 67 & 44 & 56 \\
\hline 2006 & 26 & 42 & 63 & & & 50 & 67 & 71 & 29 \\
\hline 2010 & 27 & 46 & 69 & & & 55 & 73 & 75 & 25 \\
\hline 2012 & 31 & 49 & 70 & & & 59 & 76 & 75 & 25 \\
\hline \multirow{3}{*}{ Year } & \multicolumn{7}{|c|}{ II. Number of insurers by specialization } & & \\
\hline & \multirow{2}{*}{ Monoline } & \multicolumn{6}{|c|}{ Multiline } & \multirow{2}{*}{\multicolumn{2}{|c|}{$\begin{array}{l}\text { Average per } \\
\text { firm }\end{array}$}} \\
\hline & & 2 lines & \multicolumn{2}{|c|}{3 lines } & \multicolumn{3}{|c|}{5 lines } & & \\
\hline 1995 & 158 & 13 & \multicolumn{2}{|c|}{11} & \multicolumn{3}{|c|}{49} & \multicolumn{2}{|r|}{2.21} \\
\hline 2000 & 158 & 9 & \multicolumn{2}{|c|}{13} & \multicolumn{3}{|c|}{35} & \multicolumn{2}{|r|}{2.03} \\
\hline 2005 & 136 & 6 & \multicolumn{2}{|c|}{11} & \multicolumn{3}{|c|}{30} & \multicolumn{2}{|r|}{2.00} \\
\hline 2006 & 156 & 5 & \multicolumn{2}{|c|}{10} & \multicolumn{3}{|c|}{30} & \multicolumn{2}{|r|}{1.89} \\
\hline 2010 & 121 & 11 & \multicolumn{2}{|c|}{11} & \multicolumn{3}{|c|}{28} & \multicolumn{2}{|r|}{1.94} \\
\hline 2012 & 100 & 11 & \multicolumn{2}{|c|}{7} & \multicolumn{3}{|c|}{24} & 149 & 1.95 \\
\hline
\end{tabular}

Note: All the figures in this table are after selection; see the 'Data sources' paragraph in the beginning of Section 5 for the criteria used.

\section{Empirical results}

This section presents scale economy and competition estimates, both for the total non-life sector and for individual lines of business. Health results are split into the pre-reform and post-reform years. 


\subsection{Estimates of scale economies}

We estimate Equation (3) using the data set from 1995-2012 in order to obtain a measure of scale economies (SE) for the non-life insurance market in the Netherlands. The estimates are obtained with OLS rather than panel estimations. If a fixed-effect (FE) parameter were estimated for each insurer, the average level of size or output over time would be absorbed by the FE parameter, which would eliminate the richest source of information with respect to the scale effect measurement. Table 4 presents the estimation results for this model over the entire sample period as well as separate estimates for stock and mutual insurers. All variables are deflated to 1995 prices and there is no indication of multicollinearity as no pair-wise correlation between the independent variables exceeds 0.60. In addition, we correct for heteroskedasticity using the HC3-estimator, as suggested by Davidson and MacKinnon (1993). The fourfold CRS hypothesis assumes, using the notation of Equation (1), that $\beta_{Y 1}+\beta_{Y 2}=1$ (linear), $\gamma_{Y 11}=\gamma_{Y_{22}}=0$ (quadratic) and $\gamma_{Y_{12}}=0$ (cross-output) and is rejected for all four models, see last row of Table 4 .

Table 4. Total cost model estimates for non-life insurers (1995-2012)

\begin{tabular}{|c|c|c|c|c|}
\hline \multirow[b]{2}{*}{ First output measure: } & \multicolumn{2}{|c|}{ Full data set } & \multirow{2}{*}{$\begin{array}{c}\text { Stocks } \\
\text { Premiums }\end{array}$} & \multirow{2}{*}{$\begin{array}{c}\text { Mutuals } \\
\text { Premiums }\end{array}$} \\
\hline & Premiums & Claims & & \\
\hline Gross premiums (in logs) & $0.60 * * *$ & - & $0.67 * * *$ & $0.56^{* * *}$ \\
\hline Ditto, squared ${ }^{a}$ & $-0.07 * *$ & - & $-0.04 * *$ & $-0.07 * * *$ \\
\hline Claims incurred (in logs) & - & $0.26^{* * *}$ & - & - \\
\hline Ditto, squared ${ }^{\mathrm{a}}$ & - & $-0.01 * * *$ & - & - \\
\hline Total assets (in logs) & $0.29 * * *$ & $0.56 * * *$ & $0.27 * * *$ & $0.28 * * *$ \\
\hline Ditto, squared $^{\mathrm{a}}$ & -0.04 & $-0.03 * * *$ & $0.04 *$ & $-0.05 * * *$ \\
\hline Cross term GP \& $\mathrm{TA}^{\mathrm{a}}$ & $0.12^{* *}$ & - & 0.01 & $0.14^{* * *}$ \\
\hline Cross term CI \& TA $^{a}$ & - & $0.07 * * *$ & - & - \\
\hline Wage rate (in logs) & $1.01 * * *$ & $1.64 * * *$ & $0.81 *$ & $1.31 * * *$ \\
\hline Stocks & -0.04 & $0.07 * *$ & - & - \\
\hline \multicolumn{5}{|l|}{ Lines-of-businesses } \\
\hline - Fire & $0.27 * * *$ & $0.25 * * *$ & $0.12 * * *$ & $0.33 * * *$ \\
\hline - Transport & $-0.14 * * *$ & $-0.17 * * *$ & $-0.26 * * *$ & $0.19 * * *$ \\
\hline - Health & $-0.15 * * *$ & $-0.19 * * *$ & -0.02 & $-0.24 * * *$ \\
\hline - Motor & $0.30 * * *$ & $0.39 * * *$ & $0.42 * * *$ & $0.17 * *$ \\
\hline Distribution ratio & $0.66 * * *$ & $0.74 * * *$ & $0.83^{* * *}$ & $0.42 * * *$ \\
\hline $\mathrm{HHI} / 100$ & $-0.96 * * *$ & $-0.98 * * *$ & $-0.80 * * *$ & $-0.73 * * *$ \\
\hline Time trend & $-0.01 * *$ & $-0.01 * * *$ & $-0.02 * *$ & -0.01 \\
\hline Constant & $4.27 * * *$ & $4.97 * * *$ & $4.75 * * *$ & $3.60 * * *$ \\
\hline Scale economies (SE) & 0.10 & 0.18 & 0.06 & 0.16 \\
\hline SE, $25^{\text {th }}$ percentile & 0.49 & 0.33 & 0.06 & 0.47 \\
\hline SE, $50^{\text {th }}$ percentile & 0.16 & 0.20 & 0.06 & 0.25 \\
\hline SE, $75^{\text {th }}$ percentile & -0.27 & 0.01 & 0.06 & -0.04 \\
\hline No of observations & 3,969 & 3,922 & 2,229 & 1,740 \\
\hline $\mathrm{R}^{2}$, adjusted (in \%) & 91.5 & 88.7 & 90.9 & 86.7 \\
\hline F test on CRS ${ }^{b}$ & $71.76^{* * *}$ & $103.71^{* * * *}$ & $19.90 * * *$ & $63.32 * * *$ \\
\hline
\end{tabular}

${ }^{\mathrm{a}}$ Squared and cross terms are in deviation from their average value; ${ }^{\mathrm{b}}$ Critical value of the CRS test statistic (with four restrictions and 3,953 degrees of freedom) is 3.33 at $1 \%$ significance.

Notes: The indices *, ** and *** denote significant difference from zero at, respectively, the $90 \%, 95 \%$ and $99 \%$ confidence levels. Total costs, outputs and the wage index are expressed in 1995 prices. 
We begin by discussing the first two columns of Table 4. Given the choice to include either of two output measures, premiums or claims and assets, SE is calculated as one minus the sum of the two linear output coefficients, see Equation (2). In each model, using either gross premiums or claims incurred as first output measure, we find that the non-life insurance industry in the Netherlands exhibits average scale economies as high as 10\% (premium model) or even 18\% (claim model), implying that a $1 \%$ increase in output would raise total costs by only $0.90 \%$ and $0.82 \%$, respectively. A Wald test proves that the non-linear (quadratic and cross-output) terms jointly differ significantly from zero. As a consequence, SE varies across the size distribution. Using Equation (2), we calculate scale economies for the $25^{\text {th }}, 50^{\text {th }}$ and $75^{\text {th }}$ percentile of both the premium and the total assets size distributions, see the bottom of Table 4. We observe that SE is larger for small insurers and smaller for large companies. ${ }^{7}$ This is in line with what has been found earlier for non-life (Bikker and Gorter, 2011), for life insurers (Bikker, 2012), pension funds (Bikker, 2013), and banks (Hughes and Mester, 2013). For the premiums model, we see that larger insurers face diseconomies of scale and thus are above the optimal size.

The wage index coefficient has the expected value of around 1; a Wald test on homogeneity in input prices is not rejected. ${ }^{8}$ In the 'premium' model, the cost level of stock companies is not significantly different from that of mutual insurers, whereas in the 'claims' model the stocks coefficient is significantly positive. Both results contradict the expense preference theory, which predicts stock insurers to be more cost efficient than mutuals. Bikker and Gorter (2011), Eling and Luhnen (2010) and Cummins, Rubio-Misas and Zi (2004) find higher costs for stock insurers, also in contrast to the expense preference theory. The four $L O B$ dummy variables show highly significant coefficients, with Health and Transport having significantly lower operational costs than Miscellaneous (acting as reference category), while Fire and Motor has significantly higher costs. Spending more on acquisition and distribution activities has a significant positive affect on costs, as expected. The concentration measure HHI (see Fig. 2) has a negative and highly significant effect in both models, which may point to larger possibilities of tacit collusion between insurers in a more concentrated market, or to other cost advantages of having fewer competitors. Finally, the time variable is significantly negative, reflecting the cost-reducing effect of technical progress Note that the results of the variables that represent a trend and are invariate across insurers (wage index, HHI and time) should be considered with greater caution, due to possible multicollinearity.

In the remainder of this paper we will take gross premiums as the most reliable output measure for insurance services: the alternative measure, claims, is more volatile and is slightly less success ful in explaininging total operational cost: the goodness of fit (adjusted $\mathrm{R}^{2}$ ) for gross premiums, at $91.5 \%$, is better than that for claims (88.7\%). The volatile nature of claims has a downward effect on its cost elasticity $\left(\beta_{Y_{1}}\right)$, the so-called errors-in-variable effect, which would overestimate scale economies.

7 Concavity exists when at least one of the squared output terms has a significant positive coefficient. 8 All test results are available on request from the authors. 
When we consider stocks and mutual insurers separately in the two right-hand columns of Table 4, we find lower economies of scale for stock companies (6\%) and higher SE for mutuals (16\%). This would support still the expense preference theory: stock insurers may be under more pressure than mutuals to avoid the spoil of unused scale economies. Note that for stocks SE does not vary with size, whereas it does for mutuals and also for the full sample. Other stocks coefficients are broadly in line with what we observe for the full sample.

\subsection{Scale economies and the 2006 health care reform}

An interesting question is whether the cost behavior of health insurers has changed as a consequence of the 2006 health reform. Table 5 presents the results for health insurance over the entire period, as well as for the pre- and post-reform years separately. These results are based on gross premiums as output measure, but claims yield a similar outcome, except for its higher level of SE. While Table 4 is based on all multi- and monoline insurers, we now consider health monolines only. The average SE for the full period equals $17 \%$ (significantly higher than for the full non-life sector, where we found $10 \%$ ), split into $4 \%$ before and $21 \%$ after 2006 . The effects in the reform year are in the first place due to the inclusion of the public HIFs, covering $62 \%$ of the population, in the private health insurance. These public HIFs needed to adjust to the free market where insurers compete for customers. But, in the second place, the role of private insurers also changed, e.g. insureres have now more room to negotiate with health care providers on prices and quality of care. Any interpretation of the results of

Table 5. Estimates of the health care insurance cost model (1995-2012) ${ }^{9}$

\begin{tabular}{|c|c|c|c|}
\hline & Full period & Before 2006 & After 2006 \\
\hline Gross premiums (in logs) & $0.49 * * *$ & $0.66 * * *$ & $0.41 * * *$ \\
\hline Ditto, squared ${ }^{\text {a }}$ & $-0.04 * *$ & 0.01 & -0.03 \\
\hline Total assets (in logs) & $0.34^{* * *}$ & $0.29 * * *$ & $0.38 * * *$ \\
\hline Ditto, squared ${ }^{a}$ & -0.07 & $-0.10^{* *}$ & 0.03 \\
\hline Cross term GP \& $T^{a}{ }^{a}$ & $0.09 * * *$ & $0.11^{* *}$ & 0.01 \\
\hline Wage (in logs) & $0.93 * *$ & [1] & [1] \\
\hline Distribution ratio & $1.07 * * *$ & $1.15^{* * *}$ & $0.64 * * *$ \\
\hline HHI/100 & 0.06 & $-0.37 * *$ & 0.00 \\
\hline Time & - & $0.02 * *$ & $-0.06 * * *$ \\
\hline Constant & $4.62 * * *$ & $4.05 * * *$ & 6.32 \\
\hline Scale economies (SE) & 0.17 & 0.04 & 0.21 \\
\hline SE, $25^{\text {th }}$ percentile & 0.41 & 0.26 & 0.22 \\
\hline SE, $50^{\text {th }}$ percentile & 0.21 & 0.03 & 0.22 \\
\hline SE, $75^{\text {th }}$ percentile & -0.12 & -0.17 & 0.20 \\
\hline Number of observations & 1031 & 664 & 367 \\
\hline $\mathrm{R}^{2}$, adjusted (in \%) & 88.4 & 87.5 & 91.5 \\
\hline F test on CRS ${ }^{b}$ & $44.46^{* * *}$ & $19.96^{* * *}$ & $50.17^{* * *}$ \\
\hline
\end{tabular}

See notes and footnotes below Table 4. Critical value of the CRS test statistic at $1 \%$ significance ranges from 3.34 to 3.36 , depending on the degrees of freedom.

9 Table 6 provides estimates of Equation (3), but coefficients of non-output variables are not shown, due to their low level of significance. 
the reform need to be cautious, keeping the multiple changes into account. We attribute the high level of scale economies after 2006 to increased fixed costs due to negotiations and policy strategy developments: under the new regime insurers have (i) to monitor care providers, (ii) to negotiate lower prices or higher quality with them, (iii) to develope strategic policies, and (iv) to advertise more in order to compete for clients, all items with at least substantial fixed costs. Hence, the optimal health insurer size increased after 2006. Apparently, competitive pressure in the post-2006 years has been insufficient to drive out unused scale economies. One objective of the health insurance reform was to increase competition and efficiency. Yet, while steps in the right direction may have been taken, further efficiency improvements seem possible. CRS is rejected for each of the three models (see the last row of Table 5). For the full sample and the pre-reform years scale economies decrease for larger health insurers, while the largest entities are beyond the optimal size, and therefore operate under decreasing retuns to scale. This does not hold for the post-2006 years, where SE is constant across insurer sizes and all insurers are below the optimal scale.

Turning to the other model variables, we observe that the wage coefficient value of $1-$ homogeneity in prices - is not rejected for the full sample estimation, but that the level of significance of this parameter is low. For the two subperiods wage increases have probably been too small to exert a significant influence on costs. Therefore, we restricted this parameter a value of 1 , with no consequences for the other results. The distribution ratio coefficient is positive as expected, and the concentration index HHI has a negative coefficient before 2006 (as in Table 5), and is insignificant elsewhere. The goodness-of-fit of the models is satisfactory with an adjusted $\mathrm{R}^{2}$ of around $90 \%$.

\subsection{Scale economies and the other lines-of-business}

Table 6 provides SE estimates for each of the other LOBs. For Transport we cannot reject the CRS hypothesis, possibly due to the small sample size of 123 observations (Column 2). But the linear gross premium coefficient is significantly different from 1, so scale economies exist here as well. For Fire, SE at $10 \%$ roughly equals that of the total sample, while SE of Miscellaneous, at 5\%, is substantially lower. For Fire, SE declines with size, but this 'normal' pattern is reversed for Miscellaneous. No reliable motor insurance estimates could be obtained, as the sub-sample of insurers operating solely in this LOB (only 9) was too small.

We can draw the following conclusions. Scale economies exist for all LOBs; they are largest for small firms and decline gradually with size, except for Miscellaneous. SE in health insurance is much larger for post-reform years than in the pre-reform period: apparently fixed cost increased now that insurers have to negotiate with both customers and care providers. Under fierce competition, we had not expected such unused scale economies. 
Table 6. Estimates of the total cost model per LOB (1995-2012) 10

\begin{tabular}{llll}
\hline & Fire & Transport & Miscellaneous \\
\hline Gross premiums (in logs) $_{\text {Ditto, squared }}^{\text {a }}$ & $0.69^{* * *}$ & $0.94^{* * *}$ & $0.95^{* * *}$ \\
Assets (in logs) & $-0.10^{* * *}$ & 0.09 & 0.01 \\
Ditto, squared $^{\text {a }}$ & $0.21^{* * *}$ & -0.05 & -0.00 \\
Cross term GP \& TA $^{\text {a }}$ & $-0.04^{* *}$ & 0.16 & $0.12^{* * *}$ \\
& $0.14^{* * *}$ & -0.29 & -0.09 \\
Scale economies (SE) & & & \\
Number of observations $_{\mathrm{R}^{2} \text {, adjusted (in \%) }}$ & 0.10 & 0.11 & 0.05 \\
F test on CRS $^{\mathrm{b}}$ & 1117 & 123 & 336 \\
\hline
\end{tabular}

${ }^{\mathrm{a}}$ See notes and footnotes below Table $4 .{ }^{\mathrm{b}}$ Critical value of the CRS test statistic at $1 \%$ significance ranges from 3.34 to 3.49 , depending on the degrees of freedom, and from 2.38 to 2.45 at $5 \%$ significance.

\subsection{Estimation results of the non-life PCS indicator of competition}

We estimate two variants of the PCS indicator model, with either market shares (using Equation (12) with $\beta_{t}=\beta$ for all $t$ ) or profits (Equation (11)) as independent variable, each expressed in logarithms. 11 The key explanatory variable is efficiency, where we use the estimated marginal costs (MC) as calculated according to Equation (13). As control variables we add LOB dummies which are meant to pick up part of the insurance heterogeneity. The results in Table 7 refer to both multi- and monolines for the entire sample period, 1995-2012, but excluding 2006 because for that year, we do not have lagged market shares for both new health care insurance entrees and merged health care insurers. As an alternative including 2006, we also estimated a non-dynamic version of Equation (12), that is without one-year lagged market shares (keeping $\beta_{t}=\beta$ for all $t$, see Table A.2 in the appendix).

We observe OLS estimates for $\gamma$, the lagged independent variable, in the market share model of no less than 0.98 , or in the profit model of 0.84 , see Table 7 , Columns (1) and (5). ${ }^{12}$ We ascribe these high values to (i) slow adjustment over time of market shares to marginal costs, and to (ii) persistent insurer-specific feactures. By consequence the direct impact of marginal costs on market shares, $\beta$, is small in economic terms, at -0.04 , but statistically highly significant, whereas the longterm effect, $\beta /(1-\gamma)$, is substantial at -2.54 . For profits, $\beta$ equals -0.11 and $\beta /(1-\gamma)$ is -0.66 .

The FE estimation approach may be more suitable, as it picks up persistent insurer-specific not modelled conditions which may effect markets shares or profits and hence avoids omitted variable bias. ${ }^{13} \mathrm{~A}$ disadvantage may be that $\mathrm{FE}$ estimates ignore the average levels of market shares and efficiency. For instance, an inefficiency which was persistent over the entire sample period, would be ignored. The FE coefficient of the lagged market share is only 0.69 , while it is 0.21 for lagged profits,

\footnotetext{
10 Table 6 provides estimates of Equation (3), but coefficients of distribution, claims, reinsurance, HHI and wages are not shown, as they are generally not significantly different from zero.

11 Due to the functional form of the model, companies reporting negative profits (losses) are excluded from the analysis. However, this is not expected to create a bias in the results (see Boone, 2008).

12 We use only one lagged dependent term as the one and two years lagged terms are highly correlated.

13 A random-effect model was rejected by the Wu-Hausman test, in favour of the fixed-effect model.
} 
Table 7. Estimates of the dynamic non-life PCS model (1995-2012, excl. 2006) ${ }^{14}$

\begin{tabular}{|c|c|c|c|c|c|c|c|c|}
\hline & \multicolumn{4}{|c|}{ Market share model } & \multicolumn{4}{|c|}{ Profit model } \\
\hline & OLS & & $F E$ & & OLS & & $F E$ & \\
\hline & (1) & (2) & (3) & (4) & (5) & (6) & (7) & (8) \\
\hline$\overline{M C,}, \ln$ & $-0.04^{* * *}$ & - & $-0.20 * * *$ & - & $-0.11^{* *}$ & - & $-0.52 * * *$ & - \\
\hline AC, $\ln$ & - & $-0.04 * * *$ & - & $-0.21^{* * *}$ & - & $-0.15 * * *$ & - & $-0.55^{* * *}$ \\
\hline $\begin{array}{ll}\text { Market share, } \\
\text { lag, ln }\end{array}$ & $0.98^{* * *}$ & $0.98^{* * *}$ & $0.69^{* * *}$ & $0.68 * * *$ & - & - & - & - \\
\hline $\begin{array}{l}\text { Profits, lag, } \ln \gamma \\
\text { Long-term }\end{array}$ & - & - & - & - & $0.84^{* * *}$ & $0.83^{* * *}$ & $0.21^{* * *}$ & $0.20 * * *$ \\
\hline$\beta /(1-\gamma)$ & $-2.45^{* * *}$ & $-2.39 * * *$ & $-0.64 * * *$ & $-0.65 * * *$ & $-0.66 * * *$ & $-0.88 * * *$ & $-0.65 * * *$ & $-0.69 * * *$ \\
\hline $\begin{array}{l}\text { \# of observ. } \\
\mathrm{R}^{2} \text { (overall), in \% }\end{array}$ & $\begin{array}{l}3,276 \\
98.4\end{array}$ & $\begin{array}{l}3,276 \\
98.4\end{array}$ & $\begin{array}{l}3,276 \\
(97.7)\end{array}$ & $\begin{array}{l}3,276 \\
(97.7)\end{array}$ & $\begin{array}{l}2,333 \\
79.9\end{array}$ & $\begin{array}{l}2,333 \\
80.0\end{array}$ & $\begin{array}{l}2,333 \\
(55.6)\end{array}$ & $\begin{array}{l}2,333 \\
(57.6)\end{array}$ \\
\hline
\end{tabular}

Notes: Indices *, ** and *** denote significant difference from zero at, respectively, the $90 \%, 95 \%$ and $99 \%$ confidence level. The long-term effect is calculated as $\beta /(1-\gamma)$.

see Columns (3) and (7), showing that profits are less persistent than market shares. The key parameter $\beta$ is statistically significant for marginal costs with values of -0.20 for market share and -0.52 for profits, while the long-term effects $\beta /(1-\gamma)$ are -0.64 (market shares) and -0.65 (profits). We conclude for the non-life market that both market structure and profit levels respond significantly to differences in efficiency across non-life insurers, which points at competition, and that this long-term PCS effect ranges from -0.65 to -.0 .88 .

These results are fairly well reproduced, when marginal costs calculated according to Equation (13) are replaced by average costs (AC), see columns in Table 7 with even numbers. ${ }^{15}$ Apparently, the quick-and-dirty approach of average costs as efficiency measure - ignoring fixed costs - functions well. Finally, for the market share model, the goodness of fit is very high at around 98\%, while for the - more volatile -profits it ranges from 56\% to 80\%. The non-dynamic estimates in Table A.2 in the appendix lead to the same conclusions, with PCS indicator estimates which are also highly significant but with slightly lower values (in absolute terms), due to the simplified modeling. Furthermore, comparison with Table A.2 shows that the goodness of fit in Table 7 depends heavily on the lagged independent variable. Section 6.5 goes into more details by estimating annual marginal cost elasticities $\beta_{t}$.

An absolute benchmark for the long-term effect of marginal costs on market shares or profits, $\beta /(1-\gamma)$, is absent. In order to judge the intensity of competition, we need to compare our results with similar estimates from other industries. In their study of the banking sector, Van Leuvensteijn et al. (2011) use the market share PCS model and find that the $\beta$ indicator averages -2.5 in the long-run,

\footnotetext{
14 In Tables 7, 9, A.2 and A.4 control dummies for LOB are not shown, to avoid lengthy tables. Similarly, we do not show the constant and the coefficient of 'time' in all remaining tables. However, they are available on request from the authors.

15 Average costs are less precise as they do not distinguish between fixed and variable costs, however it is quite common to approximate average variable costs by average costs.
} 
compared to our value of -0.64.16 Bikker (2012) investigates the life insurance industry using a model similar to ours, which facilitates the comparison. For the FE estimate of the long-term effect, he finds a value of -0.92, a bit larger in absolute terms than we observe for non-life (-0.64). Creusen et al. (2006) estimate the PCS model based on profits for the Dutch manufacturing and service industries and found elasticities between average variable costs and profits of around, respectively, -5.7 and -2.5 , much higher in absolute terms than our FE profit estimate of -0.65 . Hence, we conclude that the nonlife industry is less competitive than the banking, manufacturing and service industries, and even less competitive than life insurance.

\subsection{Impact of the 2006 health care reform on competition}

As we want to investigate the effect of the 2006 health care reform on competition, we also apply the PCS model to health care insurance monolines separately, both for the entire sample period and the sub-periods before and after 2006. Table 8 presents estimates using the more suitable fixed-effects approach. The long-term PCS indicator estimate of the entire sample for market shares is slightly lower, at -0.61 , than the estimate in the total non-life sample $(-0.64)$. Splitting the sample at the regime shift year 2006 shows that market shares were sticky before 2006, but respond quickly to marginal costs after the reform year. Free competition on customers have apparently worked well. The longterm PCS estimates was at -0.68 - in absolute terms - larger before 2006 than after 2006 (-0.34). The former points to quicker responses to marginal costs, while the latter suggests less strong reactions.

If we regard the profit model elasticities, we observe for the entire sample period again a somewhat lower value (long-term effects: health -0.42 versus total non life -0.65 ), but a very different pattern when we consider sub-samples for health: -1.30 after the break versus -0.50 before 2006 . Apparently, the reform had little or adverse impact on the level of market share dynamics, but substantial favourable influence on profit dynamics. Note that the reform included the transfer of the major part of health insurance from the public sector to the commercial insurance market. During the post-2006 years (until 2014), health insurers lowered prices less (than possible) in order to add profits to their solvency buffers. Efficient health insureres have enjoyed higher profits rather than gaining larger market shares. The goodness of fit is high for the health market share model for the full sample and the pre-reform years, hovering around 97\%, but low for the post-reform period and the health profit model. In Table A.3 of the appendix, we simplify our model by deleting the lagged market share (or proft) variable (that is $\gamma=0$ ), to avoid the necessary deletion of 2006 as in the dynamic original model. The results are fairly similar. Section 6.5 below discusses more detailed estimates.

16 Van Leuvensteijn et al. (2011) estimate a model without the lagged 'market share' so that $\beta$ is their long-term PCS indicator. 
Table 8. FE estimates for the dynamic health care PCS model, based on market shares (19952012, excl. 2006)

\begin{tabular}{|c|c|c|c|c|c|c|c|}
\hline & & \multicolumn{3}{|c|}{ Market share model } & \multicolumn{3}{|l|}{ Profit model } \\
\hline & & Full data set & Pre 2006 & Post 2006 & Full data set & Pre 2006 & Post 2006 \\
\hline & & (1) & $(2)$ & (3) & (4) & (5) & (6) \\
\hline $\mathrm{MC}, \ln$ & $\beta$ & $-0.20^{* * *}$ & $-0.21^{* * *}$ & $-0.35^{* * *}$ & $-0.39 * * *$ & $-0.49 * *$ & $-1.33^{* * *}$ \\
\hline $\begin{array}{l}\text { Market share, } \\
\text { lag, ln }\end{array}$ & $\gamma$ & $0.673^{* * *}$ & $0.694^{* * *}$ & -0.026 & - & - & 一 \\
\hline Profits, lag, ln & $\gamma$ & - & - & - & 0.08 & 0.02 & -0.03 \\
\hline \multicolumn{2}{|c|}{ Long-term PCS: $\beta /(1-\gamma)$} & $-0.61^{* * *}$ & $-0.68 * * *$ & $-0.34 * * *$ & $-0.42 * * *$ & $-0.50 * *$ & $-1.30 * * *$ \\
\hline \multicolumn{2}{|c|}{ \# of observations } & 843 & 533 & 310 & 505 & 319 & 186 \\
\hline \multicolumn{2}{|c|}{$\mathrm{R}^{2}$ overall (in \%) } & 96.9 & 95.9 & 25.6 & 25.3 & 4.4 & 1.0 \\
\hline
\end{tabular}

Notes: See notes to Table 7.

We estimate the PCS indicator also for the monolines of every other line of business, see Table 9. The market share model yields PCS indicators that differ significantly from zero (pointing to competition) for Fire and Miscellaneous, with long-run elasticities of -0.59 and -0.89 , respectively, but not for Transport. The profit model shows market dynamics for all three of these categories, though the evidence for Transport and Other is weak. The 'overall' goodness of fit is high for the market share model, ranging between $85 \%$ and $96 \%$, while it is much lower for the - more volatile - profits, with 32\% for Fire and Transport and 23\% for the heterogenous 'miscellaneous' category. In the nondynamic model without lagged endogenous term (see Table A.4 in the appendix), which may act as a robustness test, we find similar results, but the poor evidence in the profit model for Transport and Other becames even weaker.

We have observed significant impact of marginal costs on market shares for Health, Fire and Other, and on profits for Health and Fire, indicating competitive pressure, though less strong than in other financial and non-financial markets. Note that the Transport sample is rather small, which may explain the lower level of significance.

Table 9. FE estimates of the dynamic PCS model per LOB (1995-2012)

\begin{tabular}{|c|c|c|c|c|c|c|c|}
\hline & & \multicolumn{3}{|c|}{ Market share model } & \multicolumn{3}{|c|}{ Profit model } \\
\hline & & Fire & Transport & Other & Fire & Transport & Other \\
\hline & & (1) & (2) & (3) & (4) & (5) & (6) \\
\hline MC, $\ln$ & $\beta$ & $-0.09 * * *$ & -0.02 & $-0.40^{* *}$ & $-0.75 * * *$ & $-1.48^{*}$ & $-0.39 *$ \\
\hline Market share, lag, ln & $\gamma$ & $0.84^{* * *}$ & $0.71^{* * *}$ & $0.54^{* * *}$ & - & - & - \\
\hline Profits, lag, ln & $\gamma$ & - & - & - & $0.20 * * *$ & $0.45^{* * *}$ & 0.12 \\
\hline Long-term PCS: & $\beta /(1-\gamma)$ & $-0.59 * *$ & -0.07 & $-0.89 * * *$ & $-0.93 * * *$ & $-2.68 * *$ & $-0.45 * *$ \\
\hline \# of observations & & 965 & 89 & 273 & 815 & 61 & 185 \\
\hline $\mathrm{R}^{2}$ overall (in \%) & & 95.6 & 84.4 & 85.5 & 31.2 & 31.8 & 22.5 \\
\hline
\end{tabular}

Note: See notes to Table 7. 


\subsection{Annual estimates of the PCS indicator}

In order to capture the development of competition over time, the FE model of the PCS indicator is also estimated according to Equation (12), with a different $\beta$ for every year. Table A.5 in the appendix presents estimation details, while Fig. 4 provides the annual impact of marginal costs on health care market shares over time. This is a time-dependent variant of the market share-based PCS model of health insurers shown in the left-hand panel of Table 8. The PCS indicator follows a clear downward trend towards heavier competition in the years before 2006, possibly reflecting preparations for the reform. In 2006, the year of the health care insurance reform, competition jumps to a lower level, with $\beta$ moving from -0.68 to -0.26 . In this year huge numbers of former clients of the mandatory Health Insurance Funds (HIF, Ziekenfondsen) entered the private insurance market where, measured in numbers of insured, the HIF outnumbered the health insurance firms by a factor 1.7. Apparently, competition among these HIFs was low, or non-existent. After 2006, the PCS competition indicator resumed its regular downward path towards heavier competition without, however reaching its prereform level by 2012. These regular downward trends are remarkable as the estimated $\beta_{t}$ s are completely independent. The PCS indicator $\beta$ is significantly different from zero in most but not all years, pointing to dynamic effect of efficiency on market shares. Overall, its level in absolute terms remains fairly low.

\section{Fig. 4: The annual effect of marginal costs on health care market shares}

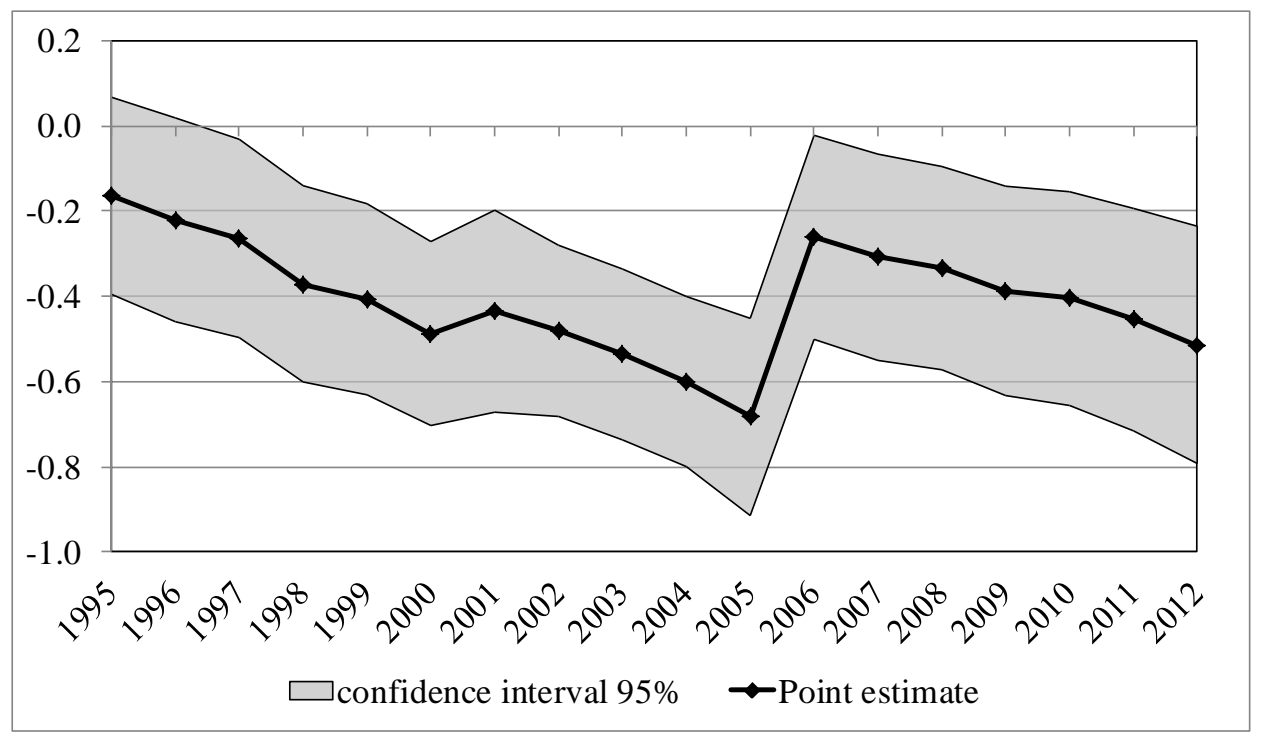

Table A.5 in the appendix and Fig. 5 present the annual effect of marginal costs on the (non-health) property and liability (P\&L) insurance market shares, using a model similarly to that shown in the lefthand panel of Table 9. The $\beta_{t}$ s are always significantly different from zero, but in absolute terms again rather low. Here too, we observe a gradual downward slope of the impact of marginal costs on market shares, but the confidence interval is to wide to draw any conclusion. 
Fig. 5: The annual effect of marginal costs on non-life market shares, excluding health

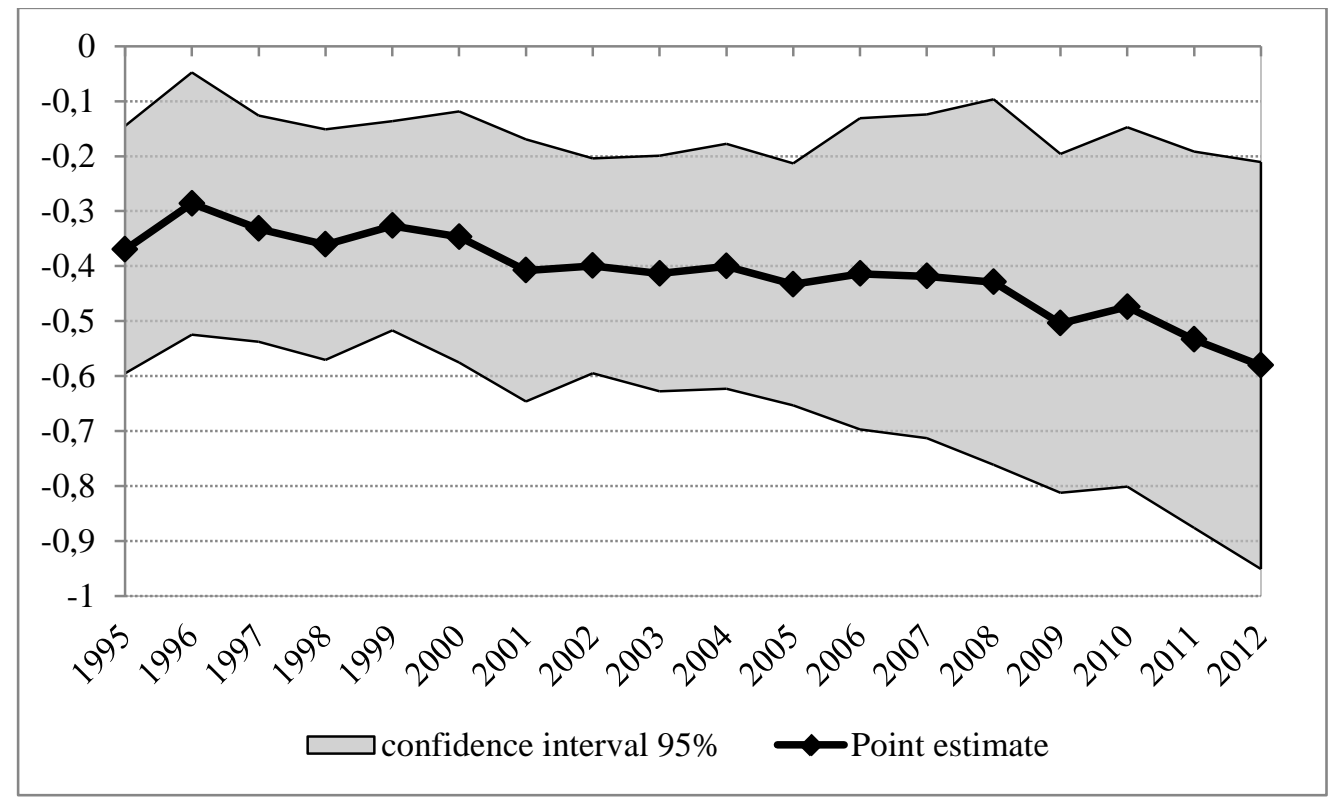

Fig. 6 presents the annual impact of marginal costs on health insurance profits, estimated with a timedependent variant on the model shown in the right-hand panel of Table 8. The graph starts with fluctuating indicator values during 1995-2002; in 1996 the indicator value was not significantly different from zero, indicating weak competition. In the running-in years to the health insurance reform, the downward trend points to strengthening of competition, reflecting preparation, exactly as in the market share model of Fig. 4. In 2006, the year of the health care insurance reform, competition

Fig. 6: The annual effect of marginal costs on health insurance profits

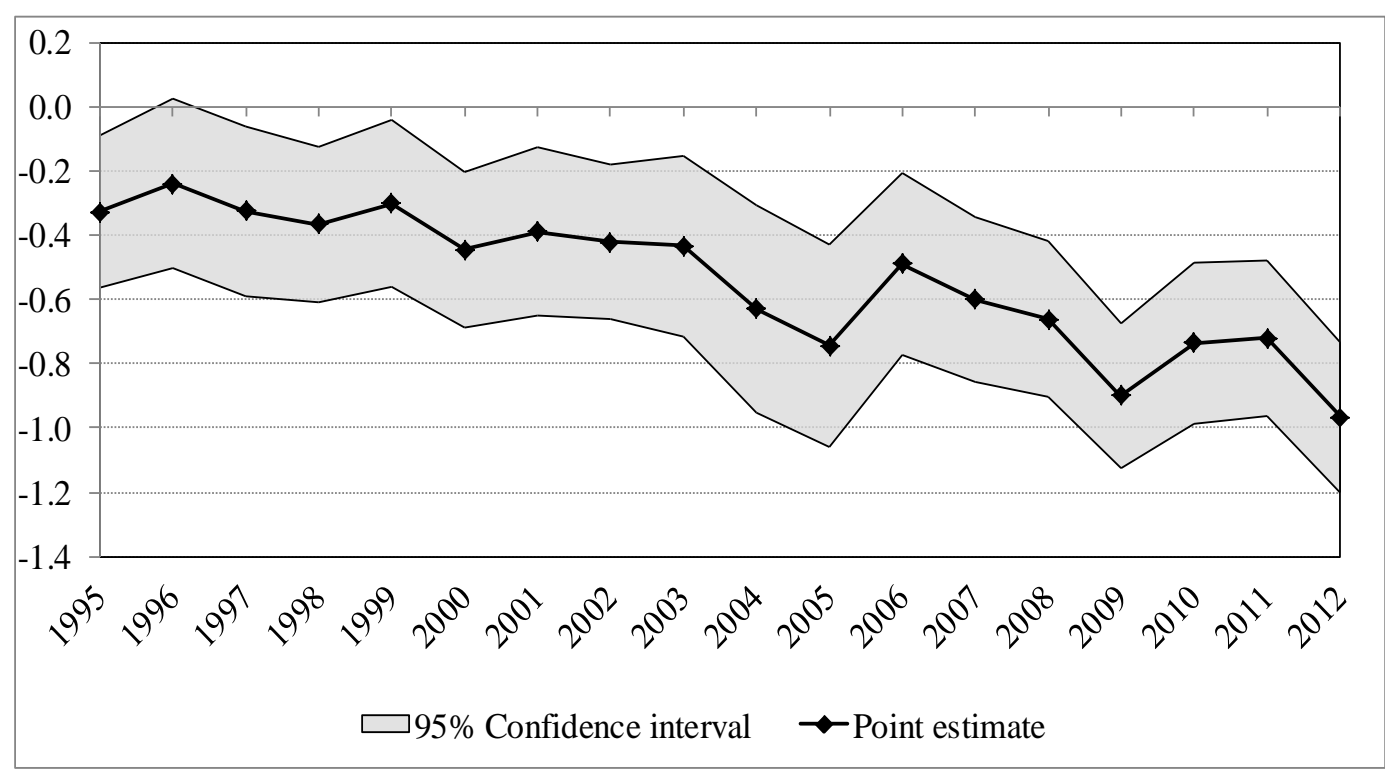


drops to a lower level, with $\beta$ moving from -0.74 to -0.49 . Huge numbers of former clients of the less-competitive - mandatory HIFs entered the private insurance market. After 2006, competition resumed its regular downward path, except in in 2010. The PCS indicator $\beta$ has a strong downward trend, pointing to increasing dynamic effects of competition on market shares, but its level, in absolute terms, so far remains fairly low.

Fig. 7: The annual effect of marginal costs on non-life insurance profits, excluding of health

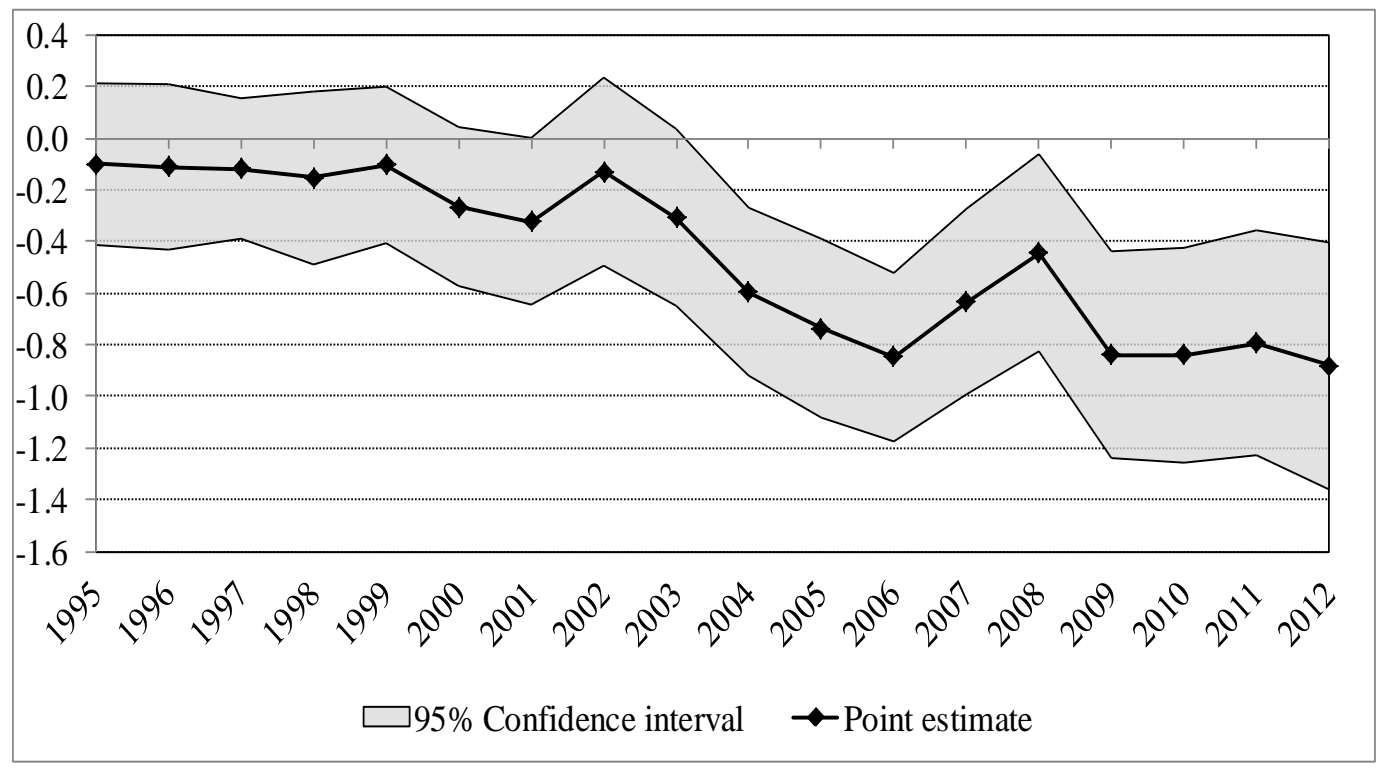

Fig. 7 presents the annual impact of marginal costs on P\&L insurance profits. Untill 2003, the PCS indicator is not significantly different from zero, suggesting weak competition, if any. In that year a downward trend starts, interrupted in 2007 and 2008, but continued thereafter. Remarkably, the pattern is rather similar to the health picture, but at a lower level of confidence and without the jump in 2006. Possibly, common (unknown) developments have had impact on both health and non health market segments. Apparently, the profit results are less convincing than the market share outcomes.

\section{Conclusions}

This paper investigates efficiency and competition of the Dutch non-life insurance market, using a unique, non-public data set covering the 1995-2012 period. The first measure is unused scale efficiency, which is expected to be low under fierce competition, and the second is the performanceconduct-structure (PCS) indicator of competition, a measurement approach never before applied to the non-life insurance industry. The paper focuses on the effects of the 2006 health insurance reform from a cost-efficiency and competition perspective, especially given the consolidation trend in the run-up to the reform. 
Analysing the data, we find that operational cost are fairly constant over the sample period, taking the insertion of public health insurance funds in 2006 into account, while profits fluctuate without a clear upward or downward trend. The number of non-life insurers fell over time by $42 \%$. Both in numbers and in terms of market share, monolines gained ground, helped by the 2006 reform, while the number of firms operating as four and five line companies fell by $75 \%$ and $50 \%$, respectively. Apparently, the benefits of specialization have outweighted those of scope economies.

For the entire non-life industry, we obtain an unused scale economy estimate for the average insurer of $10 \%$. It is much larger for smaller firms and smaller, zero or even negative for larger firms. Apparently, the larger firms hover around the optimal scale or above. Comparing stock and mutual firms, we find that the latter face significantly larger unused economies of scale (16\%) compared to the former (6\%). This may point to greater competitive pressure for stock-based insurers, in line with the expense preference hypothesis. Scale economies in health insurance are higher than in most other lines-of-business, and notably much larger after the health care reform than before: a possible interpretation is that fixed cost increased as insurers have now to monitor care providers and to negotiate lower prices with them. Under fierce competition, we do not expect such unused scale economies to persist for long.

Using the PCS indicator of competition for the entire non-life market, we have observed significant impact of marginal costs on both market shares and profits, indicating competitive pressure, though less strong than in other financial and non-financial markets. We also find significant impact of marginal costs on market shares for the Health, Fire and Other lines of business, and on profits for Health and Fire. Post-reform, the impact of marginal costs or efficiency on market shares is somewhat weaker for health insurance, due to the inclusion of the less dynamic public health insurance into the private insurer market. . In contrast, the influence of marginal cost on health insurers' profits has grown strongly since the reform, which indicates progress on at least one aim of the reform: more competition. More detailed annual estimates of the market share model reveal a gradual increase of competition since 2006. Also the remaining unused scale economies in health insurance underline that it may take longer before the fruits of the reform can be harvested in full.

\section{Bibliography}

Berger, A.N., Cummins, D.J., Weiss, M.A., and Zi, H. (2000). Conglomeration versus strategic focus: evidence from the insurance industry. Journal of Financial Intermediation 9, 323-362.

Bikker, J.A., and Bos, J. (2008). Bank Performance: A theoretical and empirical framework for the analysis of profitability, competition and efficiency. London and New York: Routledge International Studies in Money and Banking.

Bikker, J.A., and van Leuvensteijn, M. (2008), Competition and efficiency in the Dutch life insurance industry. Applied Economics 40, 2063-2084.

Bikker, J.A., and Gorter, J.K. (2011). Restructuring of the Dutch nonlife insurance industry: consolidation, organisational form and focus. The Journal of Risk and Insurance 78, 163-184.

Bikker, J.A. (2012). Performance of the life insurance industry under pressure: efficiency, competition and consolidation, DNB Working Paper No. 357, De Nederlandsche Bank, Amsterdam. 
Bikker, J.A. (2013). Is there an optimal pension fund size? A scale-economy analysis of administrative and investment costs, DNB Working Paper No. 376, De Nederlandsche Bank, Amsterdam.

Bikker, J.A., M. van Leuvensteijn (2014). Measuring Competition in the Financial Industry: The Performance-Conduct-Structure Indicator, Routledge, Londen \& New York.

Boone, J., 2001, Intensity of competition and the incentive to innovate, International Journal of Industrial Organization 19, 705-726.

Boone, J. (2008). A new way to measure competition, Economic Journal 118, 1245-1261.

Bos, J.W.B. (2004) Does market power affect performance in the Dutch banking market? A comparison of reduced form market structure models, De Economist 152, 491-512.

Capgemini. (2012). World Insurance Report 2012. Capgemini, www.nl.capgemini.com/resource-fileaccess/resource/pdf/World_Insurance_Report_2012.pdf.

Creusen, H., B. Minne, and H. Van der Wiel (2006). Competition in the Netherlands: an analysis of the period 1993-2001, CPB Document No. 136, CPB Netherlands Bureau for Economic Policy Analysis, The Hague.

Cummins, J.D., and Weiss, M.A. (2000). Analyzing firm performance in the insurance industry using frontier efficiency and productivity methods. In G. Dionne (Ed.), Handbook of Insurance. Boston: Kluwer Academic Publishers.

Cummins, J.D., Rubio-Misas, M., and Zi, H. (2004). The effect of organizational structure on efficiency: evidence from the Spanish insurance industry. Journal of Banking and Finance 28, 3113-3150.

Cummins, J.D., and Rubio-Misas, M. (2006). Deregulation, consolidation and efficiency: evidence from the Spanish insurance industry. Journal of Money, Credit and Banking 38, 323-355.

Cummins, J.D, Weiss, M.A., Xie, X., and Zi, H. (2010). Economies of scope in financial services: a DEA efficiency analysis of the US insurance industry. Journal of Banking and Finance 34, 1525-1539.

Cummins, J.D., and Xie, X. (2013). Efficiency, productivity, and scale economies in the US propertyliability insurance industry, Journal of Productivity Analysis 39, 141-164.

Cummins, J.D., and Weiss, M.A. (2014). Analyzing firm performance in the insurance industry using frontier efficiency and productivity methods. In G. Dionne (Ed.), Handbook of Insurance Economics. Boston: Kluwer Academic Publishers, 2nd ed..

Daley, C., and Gubb, J. (2011). Healthcare Systems:The Netherlands. Civitas.

Davidson, R., and MacKinnon, J. (1993). Estimation and Inference in Econometrics. New York: Oxford University Press.

De Young, R. (1998). Management quality and X-inefficiency in national banks. Journal of Financial Services Research 13, 5-22.

Eling, M., and Luhnen, M. (2010). Efficiency in the international insurance industry: A cross-country comparison. Journal of Banking and Finance 34, 1497-1509.

Fecher, F., Perelman, S., and Pestieau, P. (1991). Scale economies and performance in the French insurance industry. The Geneva Papers on Risk and Insurance 16, 315-326.

Fenn, P., Vencappa, D., Diacon, S., Klumpes , P., and O’Brien, C. (2008). Market structure and the efficiency of European insurance companies:A stochastic frontier analysis. Journal of Banking and Finance 32, 86-100.

Grace, M.F., and Timme, S. G. (1992). An examination of cost economies in the United States life insurance industry. Journal of Risk and Insurance 59, 72-103.

Greß, S., Manouguian, M., and Wasem, J. (2007). Health Insurance Reform in the Netherlands. CESifo DICE Report nr. 1.

Hanweck, G.A., and Hogan, A.M. (1996). The structure of the property/casualty insurance industry. Journal of Economics and Business 48, 141-155.

Hay, D.A., and Liu, G.S. (1997). The efficiency of firms: what difference does competition make? The Economic Journal 107, 597-617.

Hirao, Y., and Inoue, T. (2004). On the cost structure of the Japanese property-causality insurance industry. The Journal of Risk and Insurance 71, 501-530.

Hughes, J., and Mester, L. (2013). Who said large banks don't experience scale economies? Evidence from a risk-return-driven cost function, Journal of Financial Intermediation 22, 559-585. 
Jensen, M. (1986). Agency costs of free cash flow, corporate finance and takeovers. American Economic Review 76, 323-329.

Kasman, A., and Turgutlu, E. (2009). Cost efficiency and scale economies in the Turkish insurance industry. Applied Economics 41, 3151-3159.

Kellner, S., and Mathewson, F. (1983). Entry, size distribution, scale, and scope economies in the life insurance industry. Journal of Business 56, 25-44.

Leu, R.E., Rutten, F.F., Brouwer, W., Matter, P., and Rütschi, C. (2009). The Swiss and the Dutch health insurance systems: universal coverage and regulated competitive insurance markets. The Commonwealth Fund.

Mayers, D., and Smith, C.W. (1988). Ownership structure across lines of property-casualty insurance. Journal of Law and Economics 31, 351-378.

Mayers, D., and Smith, C.W. (1994). Managerial discretion and stock insurance company ownership structure. Journal of Risk and Insurance 61, 638-655.

Meador, J.W., Harley, R.E., and Schellhorn, C.D. (1998). product focus versus diversification: estimates of X-efficiency for the US life insurance industry. Working Paper, Northeastern University Boston, MA.

Oosenbrug, A. (2007). Insurance in the Netherlands: market structure and recent developments. In D. Cummins, and B. Venard (Eds.), Handbook of International Insurance: Between Global Dynamics and Local Contingencies (Vol. 26, 455-497). Springer.

Rai, A. (1996). Cost efficiency of international insurance firms. Journal of Financial Services Research 10, 213-233.

Raith, M. (2003). Competition, risk, and managerial incentives. The American Economic Review 93, $1425-1436$.

Ruthenberg, D., and Elias, R. (1996). cost economies and interest rate margins in a unified European banking market. Journal of Economics and Business 48, 231-249.

Schäfer, W., Kroneman, M., Boerma, W., Van den Berg, M., Westert, G., Devillé, W. (2010). The Netherlands: Health system review. Health systems in Transition 12, 1-229.

Swiss Re. (2011). World insurance in 2010, Sigma nr. 2, Zurich, Switzerland.

Swiss Re. (2013). World insurance in 2012, Sigma nr. 3, Zurich, Switzerland (update January 2014).

Teece, D. (1980). Economies of scope and the scope of enterprise. Journal of Economic Behavior and Organization 1, 233-247.

Theil, H. (1969). A multinomial extension of the linear logit model, International Economic Review 10, 251-259.

Van den Ven, W.P., and Schut, F.T. (2009). Managed competition in the Netherlands: Still work-inprogress. Health Economics18, 253-255.

Van Leuvensteijn, M., Bikker, J.A., van Rixtel, A., and Kok-Sørensen, C. (2011). A new approach to measuring competition in the loan markets of the euro area. Applied Economics 43, 3155-3167.

Verbond van Verzekeraars (2011). Dutch insurance industry in figures 2011. The Hague: Verbond van Verzekeraars.

Yuengert, A. (1993). The measurement of efficiency in life insurance: estimates of a mixed normalgamma error model. Journal of Banking and Finance 17, 483-496. 


\section{Appendix. Data and estimates}

Table A.1. Sample averages of approximated non-life insurance lines of business (2012)

\begin{tabular}{|c|c|c|c|c|c|c|}
\hline & \multirow[t]{2}{*}{ Total } & \multicolumn{4}{|c|}{ Mono- and multiline firms with at least: ${ }^{a}$} & \multirow[b]{2}{*}{ Other } \\
\hline & & Health & Fire & Transport & Motor & \\
\hline 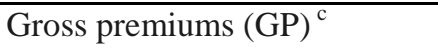 & 374,377 & 657,721 & 166,926 & 377,927 & 366,976 & 265,960 \\
\hline Total assets (TA) ${ }^{\mathrm{c}}$ & 501,901 & 856,722 & 393,322 & 890,521 & 852,118 & 633,315 \\
\hline Claims/GP & 0.82 & 0.84 & 0.66 & 0.67 & 0.68 & 0.63 \\
\hline Operational costs ${ }^{\mathrm{b}} / \mathrm{GP}$ & 0.12 & 0.11 & 0.29 & 0.29 & 0.29 & 0.28 \\
\hline Profits/GP & 0.04 & 0.04 & 0.02 & 0.01 & 0.02 & 0.02 \\
\hline Net investment income/GP & 0.04 & 0.04 & 0.07 & 0.07 & 0.08 & 0.07 \\
\hline$\%$ of stock insurers & 84.6 & 84.4 & 97.6 & 98.9 & 98.5 & 98.4 \\
\hline Distribution ratio (Acq.) & 65.1 & 82.9 & 58.5 & 79.4 & 88.9 & 83.9 \\
\hline Reinsurance/GP & 0.06 & 0.06 & 0.20 & 0.20 & 0.20 & 0.20 \\
\hline $\mathrm{HHI}^{\mathrm{d}}$ & 0.07 & 0.06 & 0.10 & 0.09 & 0.09 & 0.14 \\
\hline Share of total non-life market ${ }^{\mathrm{e}}$ & 100.0 & 49.7 & 12.6 & 11.8 & 12.2 & 13.7 \\
\hline Equity/TA & 0.27 & 0.26 & 0.23 & 0.21 & 0.21 & 0.22 \\
\hline Number of insurers & 149 & 82 & 82 & 34 & 36 & 56 \\
\hline
\end{tabular}

Notes: ${ }^{\text {a }}$ The approximate LOB numbers refer to companies, that have at least the respective LOB in their portfolio, but possibly also other $\mathrm{LOB} ;{ }^{\mathrm{b}}$ Operational costs are defined as management and acquisition costs. ${ }^{\mathrm{c}}$ In thousands of euro, 2010 prices; ${ }^{\mathrm{d}} \mathrm{HHI}$ is defined as squared market shares of insurers in gross premiums (in basis points); ${ }^{\mathrm{e}}$ Based on gross premiums

Table A.2. Estimates of the non-dynamic non-life PCS model (1995-2012)

\begin{tabular}{|c|c|c|c|c|c|c|c|c|}
\hline & \multicolumn{4}{|c|}{ Market share model } & \multicolumn{4}{|c|}{ Profit model } \\
\hline & \multicolumn{2}{|l|}{ OLS } & \multicolumn{2}{|l|}{$F E$} & \multicolumn{2}{|l|}{ OLS } & \multicolumn{2}{|l|}{$F E$} \\
\hline & (1) & $(2)$ & (3) & (4) & (5) & (6) & (7) & (8) \\
\hline MC, ln & $-0.53^{* * *}$ & - & $-0.37^{* * *}$ & - & $-0.26^{* * *}$ & - & $-0.43^{* * *}$ & - \\
\hline$A C, \ln$ & - & $-0.69^{* * *}$ & - & $-0.39^{* * *}$ & - & $-0.46^{* * *}$ & - & $-0.46^{* * *}$ \\
\hline \# of observ. & 3,735 & 3,735 & 3,735 & 3,735 & 3,034 & 3,034 & 3,034 & 3,034 \\
\hline $\mathrm{R}^{2}$ overall & 48.7 & 50.7 & $(17.0)$ & $(21.8)$ & 33.8 & 35.1 & $(9.0)$ & (12.9) \\
\hline
\end{tabular}

Note: See notes to Table 7.

Table A.3. FE estimates for the non-dynamic health care PCS model, based on market shares (1995-2012)

\begin{tabular}{lllllll}
\hline & \multicolumn{5}{l}{ Market share model } & \multicolumn{3}{l}{ Profit model } \\
\cline { 2 - 7 } & Full data set & Pre 2006 & Post 2006 & Full data set & Pre 2006 & Post 2006 \\
\cline { 2 - 7 } & $(1)$ & $(2)$ & $(3)$ & $(4)$ & $(5)$ & $(6)$ \\
\hline MC, ln & $-0.33^{* * *}$ & $-0.30^{* *}$ & $-0.34^{* * *}$ & $-0.57^{* * *}$ & $-0.50^{* *}$ & $-1.55^{* * *}$ \\
& & & & & & \\
\# of observations & 1013 & 653 & 360 & 746 & 482 & 264 \\
$\mathrm{R}^{2}$ overall (in \%) & 26.5 & 5.0 & 42.3 & 11.8 & 2.4 & 14.5 \\
\hline
\end{tabular}

Note: See notes to Table 8. 
Table A.4. FE estimates of the non-dynamic PCS model per LOB (1995-2012)

\begin{tabular}{lllllll}
\hline & \multicolumn{5}{l}{ Market share model } & \multicolumn{2}{l}{ Profit model } \\
\cline { 2 - 7 } & Fire & Transport & Other & Fire & Transport & Other \\
\cline { 2 - 7 } & $(1)$ & $(2)$ & $(3)$ & $(4)$ & $(5)$ & $(6)$ \\
\hline MC, ln & $-0.26^{* *}$ & -0.15 & $-0.57^{* *}$ & $-0.56^{* * *}$ & -0.08 & $-0.34^{*}$ \\
\# of observations & 1099 & 105 & 318 & 983 & 84 & 253 \\
$\mathrm{R}^{2}$ overall (in \%) & 3.1 & 0.4 & 0.0 & 1.4 & 14.3 & 6.2 \\
\hline
\end{tabular}

Note: See notes to Table 7.

Table A.5. PCS model estimates over time, based on marginal cost

\begin{tabular}{lllll}
\hline & Health & & \multicolumn{2}{l}{ Non-life insurance, excluding health } \\
\cline { 2 - 4 } Marginal costs & Market shares & Profit & Market shares & Profit \\
\hline 1995 & -0.16 & $-0.33^{* * *}$ & $-0.37^{* * *}$ & -0.1 \\
1996 & $-0.22^{*}$ & $-0.24^{*}$ & $-0.29^{* *}$ & -0.11 \\
1997 & $-0.26^{* *}$ & $-0.33^{* *}$ & $-0.33^{* * *}$ & -0.12 \\
1998 & $-0.37^{* * *}$ & $-0.37^{* * *}$ & $-0.36^{* * *}$ & -0.15 \\
1999 & $-0.41^{* * *}$ & $-0.30^{* *}$ & $-0.33^{* * *}$ & -0.1 \\
2000 & $-0.49^{* * *}$ & $-0.45^{* * *}$ & $-0.35^{* * *}$ & $-0.26^{*}$ \\
2001 & $-0.43^{* * *}$ & $-0.39^{* * *}$ & $-0.41^{* * *}$ & $-0.32^{* *}$ \\
2002 & $-0.48^{* * *}$ & $-0.42^{* * *}$ & $-0.40^{* * *}$ & -0.13 \\
2003 & $-0.54^{* * *}$ & $-0.43^{* * *}$ & $-0.41^{* * *}$ & $-0.31^{* *}$ \\
2004 & $-0.60^{* * *}$ & $-0.63^{* * *}$ & $-0.40^{* * *}$ & $-0.59^{* * *}$ \\
2005 & $-0.68^{* * *}$ & $-0.74^{* * *}$ & $-0.43^{* * *}$ & $-0.74^{* * *}$ \\
2006 & $-0.26^{* *}$ & $-0.49^{* * *}$ & $-0.41^{* * *}$ & $-0.85^{* * *}$ \\
2007 & $-0.31^{* *}$ & $-0.60^{* * *}$ & $-0.42^{* * *}$ & $-0.63^{* * *}$ \\
2008 & $-0.33^{* * *}$ & $-0.66^{* * *}$ & $-0.43^{* *}$ & $-0.44^{* *}$ \\
2009 & $-0.39^{* * *}$ & $-0.90^{* * *}$ & $-0.50^{* * *}$ & $-0.84^{* * *}$ \\
2010 & $-0.40^{* * *}$ & $-0.74^{* * *}$ & $-0.47^{* * *}$ & $-0.84^{* * *}$ \\
2011 & $-0.45^{* * *}$ & $-0.72^{* * *}$ & $-0.53^{* * *}$ & $-0.79^{* * *}$ \\
2012 & $-0.51^{* * *}$ & $-0.97^{* * *}$ & $-0.58^{* * *}$ & $-0.88^{* * *}$ \\
Time & $-0.13^{* * *}$ & & -0.01 & -0.01 \\
Constant & $-10.43^{* * *}$ & $1.65^{* * *}$ & $-13.53^{* * *}$ & $0.38^{*}$ \\
Number of obs. & 1031 & 746 & 1584 & 1321 \\
$\mathrm{R}^{2}$ within (in \%) & 52.9 & 17.3 & 11.1 & 14.7 \\
$\mathrm{R}^{2}$ between (in \%) & 0.1 & 14.8 & 0.6 & 2.0 \\
$\mathrm{R}^{2}$ overall (in \%) & 4.1 & 13.8 & 3.0 & 4.8 \\
\hline
\end{tabular}

